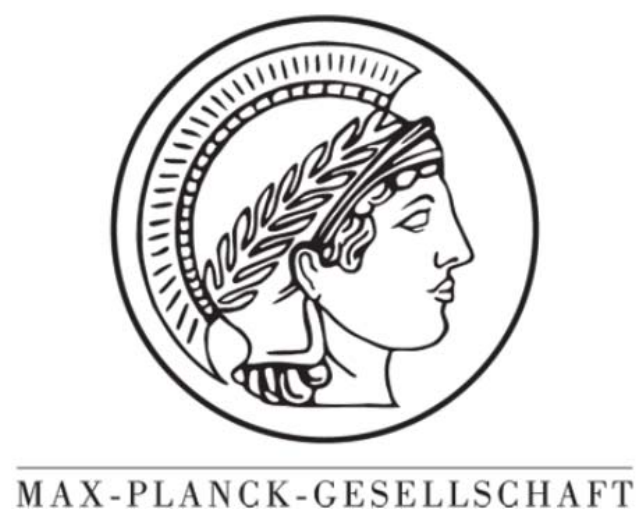

Originally published as:

Beck, B., Harth, M., Hamilton, N., Carrero, C., Uhlrich, J., Trunschke, A., Shaikhutdinov, S.K., Schubert, H., Freund, H.-J., Schlögl, R., Sauer, J., Schomäcker, R.

Partial oxidation of ethanol on vanadia catalysts on supporting oxides with different redox properties compared to propane

Journal of Catalysis, 296, 120-131. doi:10.1016/j.jcat.2012.09.008 


\title{
Partial oxidation of ethanol on vanadia catalysts on supporting oxides with different redox properties compared to propane
}

\author{
Benjamin Beck ${ }^{\mathrm{a}}$, Manuel Harth ${ }^{\mathrm{b}}$, Neil G. Hamilton ${ }^{\mathrm{c}}$, Carlos Carrero ${ }^{\mathrm{a}}$, John J. Uhlrich ${ }^{\mathrm{d}}$, \\ Annette Trunschke ${ }^{c}$, Shamil Shaikhutdinov ${ }^{d}$, Helmut Schubert ${ }^{b}$, Hans-Joachim Freund ${ }^{d}$, \\ Robert Schlögl ${ }^{\mathrm{c}}$, Joachim Sauer ${ }^{\mathrm{e}}$, Reinhard Schomäcker ${ }^{\mathrm{a}, *}$ \\ ${ }^{a}$ Technical University Berlin, Department of Chemistry, Straße des 17. Juni 124, 10623 Berlin, Germany \\ ${ }^{\mathrm{b}}$ Technical University Berlin, Department of Material Science, Hardenbergstraße 40, 10623 Berlin, Germany \\ ${ }^{\mathrm{c}}$ Fritz-Haber-Institute of the Max-Planck Society, Department of Inorganic Chemistry, Faradayweg 4-6, 14195 Berlin, Germany \\ ${ }^{\mathrm{d}}$ Fritz-Haber-Institute of the Max-Planck Society, Department of Chemical Physics, Faradayweg 4-6, 14195 Berlin, Germany \\ e Institute of Chemistry, Humboldt University, Unter den Linden 6, 10099 Berlin, Germany
}

\section{A R T I C L E I N F O}

\section{Article history:}

Received 10 July 2012

Revised 8 September 2012

Accepted 13 September 2012

Available online 13 October 2012

\section{Keywords:}

Oxidative dehydrogenation

Supported vanadia catalysts

Ethanol

Propane

Bell-Evans-Polanyi

\begin{abstract}
A B S T R A C T
The influence of the support material of vanadia catalysts on the reaction rate, activation energies, and defect formation enthalpies was investigated for the oxidative dehydrogenation of ethanol and propane. Characterization by infrared absorption-reflection spectroscopy (IRAS), Raman and UV-vis spectroscopy verifies a high dispersion of vanadia for powder and thin-film model catalysts. The support effect of ceria, alumina, titania, and zirconia is reflected in activation energy, oxidative dehydrogenation (ODH) rate, and temperature-programmed reductions (TPR) for both catalyst systems, ethanol and propane. Impendence spectroscopy and density functional theory (DFT) calculations were used to determine the defect formation enthalpy of the vanadyl oxygen double bond, providing the scaling parameter for a BellEvans-Polanyi relationship. On the basis of a Mars-van-Krevelen mechanism, an energy profile for the oxidative dehydrogenation is proposed.
\end{abstract}

(c) 2012 Elsevier Inc. All rights reserved.

\section{Introduction}

In the last two decades, vanadia-based catalysts have been intensively studied for partial oxidation $[1,2]$ or oxidative dehydrogenation $(\mathrm{ODH})$ reactions $[3,4]$. They represent a worthwhile alternative for the production of short alkenes like ethene and propene, because these reactions are exothermic and not thermodynamically limited. Olefins are fundamental raw materials for a lot of industrial processes such as the production of polypropylene, acrylonitrile, and propylene oxide [5], whose demand underlies a steady increase. Today, the major part of the ethene and propene production is actually done by energy consuming steam cracking and thermal dehydrogenation processes, and it is reasonable to suspect that these processes cannot cover the demand. At present, for the ODH of short alkanes, selectivity to the desired alkenes is not satisfactory, because the products are prone to total oxidation by the catalysts.

In many studies, a strong impact of the support material on the activity of the surface vanadyl species in various ODH reactions of hydrocarbons and alcohols [1,3,6-9] has been reported. Attempts

\footnotetext{
* Corresponding author.

E-mail address: Schomaecker@tu-berlin.de (R. Schomäcker).
}

have been made to correlate the activity with a single global parameter, the Sanderson electro negativity [1]. Some authors $[3,6,8]$ assume that the influence of the support onto the reducibility of the surface vanadia species controls the activity. However, the attempt to correlate the propane oxidation activity with the peak maxima of $\mathrm{H}_{2}$-TPR experiments as a function of the support material $[3,8,10]$ often leads to unsatisfactory results. Density functional theory (DFT) calculations [11,12] suggest to use oxygen defect formation energies of supported vanadia as reactivity descriptors $[13,14]$. For vanadia supported on ceria, DFT calculations of oxygen defect formation energies have been used to rationalize the observed increased formation rate of formaldehyde compared to vanadia on inert supports [15]. This is in the spirit of linear free energy relationship (Bell-Evans-Polanyi principle) $[6,16]$, which have been successfully used to rationalize trends in the catalytic activity of transition metals [1].

The aim of this work is to provide deeper insight into the nature of the support effect by comparison of defect formation energies obtained through impedance spectroscopy with reaction data on powder catalysts as well as by comparison with model systems. The oxidative dehydrogenation of propane, which we investigated [3] earlier, is not well suited as test reaction for catalyst properties because of the influence of consecutive reactions to the primary 
ODH reaction, which have to be considered in the kinetic analysis. The latter cannot be neglected in detailed kinetic descriptions of the primary ODH reaction even at low reactant conversions. Therefore, we choose the partial oxidation of ethanol as probe reaction. This reaction runs with very high selectivity to the desired aldehyde and is also very sensitive to the support material $[2,17,18]$.

$\mathrm{C}_{2} \mathrm{H}_{5} \mathrm{OH}+0.5 \mathrm{O}_{2} \rightarrow \mathrm{C}_{2} \mathrm{H}_{4} \mathrm{O}+\mathrm{H}_{2} \mathrm{O} \quad \Delta_{\mathrm{R}} \mathrm{H}=-179 \mathrm{~kJ} / \mathrm{mol}$

$\mathrm{C}_{3} \mathrm{H}_{8}+0.5 \mathrm{O}_{2} \rightarrow \mathrm{C}_{3} \mathrm{H}_{6}+\mathrm{H}_{2} \mathrm{O} \quad \Delta_{\mathrm{R}} \mathrm{H}=-118 \mathrm{~kJ} / \mathrm{mol}$

In order to deduce the role of the support material on the reactivity of vanadia, vanadia was deposited in sub-monolayer quantities on alumina, zirconia, titania, and ceria as support materials. The supported vanadia catalysts were characterized by UVvis and Raman spectroscopy, temperature-programmed reduction (TPR), nitrogen adsorption, inductively coupled plasma optical emission spectroscopy (ICP-OES), impedance spectroscopy and tested for their catalytic capabilities in ethanol dehydrogenation to acetaldehyde. For the investigation of the oxygen defect formation as reactivity descriptor of the catalysts, the defect formation energies were determined by impedance spectroscopy and compared to theoretical predictions.

Additionally, vanadia was deposited in sub-monolayer quantities on the surfaces of ceria and alumina thin films as model supports. The respective experimental model systems were studied by temperature-programmed desorption (TPD) and infrared absorption-reflection spectroscopy (IRAS) in order to elucidate structure-reactivity relationships for ethanol oxidations at systems where structure and morphology had been investigated previously with the scanning tunneling microscope (STM) and proven to be analogous. DFT has been applied to calculate oxygen defect formation energies for models of the different supported catalysts in order to demonstrate the significant differences between the two systems.

\section{Experimental}

\subsection{Thin-film model catalysts}

The experiments were performed in an ultrahigh vacuum (UHV) chamber with a base pressure of $\sim 5 \times 10^{-10} \mathrm{mbar}$. The chamber is equipped with an IR spectrometer (Bruker IFS 66/vs), a differentially pumped quadrupole mass spectrometer (Hiden HAL 201), and a low energy electron diffraction/Auger electron spectroscopy (LEED/AES, from Specs). The single crystal substrates $(\mathrm{Ru}(0001)$ for the ceria films and $\operatorname{NiAl}(110)$ for the alumina films, both from Mateck) were spot-welded to two parallel Ta wires, which are in turn welded to two Ta rods used for resistive heating up to $1300 \mathrm{~K}$ and also for cooling down to $100 \mathrm{~K}$ by filling a manipulator rod with liquid nitrogen. The temperature is measured by a chromel-alumel thermocouple spot-welded to the underside of the crystal.

The ca. $5 \mathrm{~nm}$ thick, well-ordered $\mathrm{CeO}_{2}(111)$ films were grown as described elsewhere $[19,20]$. Briefly, the $\mathrm{Ru}(0001)$ substrate was cleaned with repeated cycles of ion sputtering and annealing in UHV at $1300 \mathrm{~K}$. Then, the Ru substrate was precovered with oxygen at $700 \mathrm{~K}$ in $1 \times 10^{-6} \mathrm{mbar}_{2}$ for $5 \mathrm{~min}$. Ceria was evaporated onto this surface in $1 \times 10^{-6} \mathrm{mbar}_{2}$ from a tungsten crucible contained in an e-beam-assisted evaporator (EFM3 from Omicron). The film was oxidized at $980 \mathrm{~K}$ in $1 \times 10^{-6} \mathrm{mbar}_{2}$ for $15 \mathrm{~min}$, resulting in a film which showed a sharp $(1.4 \times 1.4)-\mathrm{Ru}(0001)$ LEED pattern (not shown) with low background intensity characteristic for the crystalline $\mathrm{CeO}_{2}(111)$ thin films [19].

The alumina films were grown using a well-established procedure on $\mathrm{NiAl}(110)[21,22]$. The NiAl substrate was cleaned with repeated cycles of sputtering and annealing in UHV at $1300 \mathrm{~K}$ for 5 min. Then, $\sim 1200 \mathrm{~L} \mathrm{O}_{2}\left(1 \mathrm{~L}=1 \times 10^{-6}\right.$ Torr s $)$ was dosed onto the surface $\left(1 \times 10^{-6}\right.$ mbar $\mathrm{O}_{2}$ for $\left.20 \mathrm{~min}\right)$ at a temperature of $550 \mathrm{~K}$, followed by annealing in UHV at $1075 \mathrm{~K}$ for $5 \mathrm{~min}$. This dosing and annealing cycle was then repeated in order to assure a closed film. The sample exhibited the LEED pattern (not shown) and characteristic phonon $\left(\sim 865 \mathrm{~cm}^{-1}\right)$ of the crystalline $\mathrm{Al}_{2} \mathrm{O}_{3} /$ $\operatorname{NiAl}(110)$ film [21].

For both films, vanadia particles were deposited onto the surface at two different sub-monolayer coverages. The sample was biased at the same potential as the source rod during evaporation in order to prevent the acceleration of ions toward the sample. The evaporations were conducted at $300 \mathrm{~K}$ in $1 \times 10^{-6} \mathrm{mbar}_{2}$. After the evap-

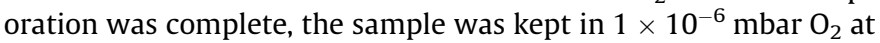
$300 \mathrm{~K}$ for 10 additional minutes, in order to ensure complete oxidation of the particles. The surface was then exposed to ca. 25 L ethanol (>99.8\% purity, further purified with repeated freezepump-thaw cycles) using a directional pinhole doser at $300 \mathrm{~K}$. The sample was cooled to ca. $100 \mathrm{~K}$ prior to temperature-programmed desorption (TPD) measurements. The TPD spectrum was acquired at a heating rate of $3 \mathrm{~K} / \mathrm{s}$ up to $700 \mathrm{~K}$, and the relevant masses of desorbed species were monitored using a mass spectrometer. The TPD signal for $m / z=29$ is a characteristic component for acetaldehyde cracking pattern and was used to determine the degree of acetaldehyde formation. In order to correct this signal for the desorption of ethanol (which also has a component at $29 \mathrm{amu}$ ), the following equation was used $\boldsymbol{I}^{F A}=\boldsymbol{I}^{(m / z=29)}-1.6 \times \boldsymbol{I}^{(m / z=31)}$, where the correction factor of 1.6 was empirically determined for our measurement system using the desorption of a multilayer of physisorbed ethanol.

\subsection{DFT calculations}

DFT plane wave calculations have been performed on slab models of vanadia species supported on the $\mathrm{CeO}_{2}(111)$ surface [23] and on the thin alumina film grown on a NiAl substrate [24] as described before. The same methods are applied to vanadia species supported on the $\gamma-\mathrm{Al}_{2} \mathrm{O}_{3}(001)$ surface. A slab model with a $1 \times 2$ surface cell was adopted for a vanadia loading of $\Theta=0.25$. The Perdew-Wang 91 (PW91) functional is applied, except for ceria for which the PBE + D approximation is employed, see Ref. [23] for details.

\subsection{Powder catalysts}

The powder catalysts were prepared by the thermal spreading of a vanadyl acetylacetonate (Fluka) precursor over each support material. Titania (anatase), zirconia, and alumina, which were obtained from Saint-Gobain Norpro, and ceria, which was prepared in our laboratory by thermal decomposition of cerium nitrate (ABCR), were selected as support materials. Each support was precalcined at $750{ }^{\circ} \mathrm{C}$ for $4 \mathrm{~h}$ before being well mixed with the appropriate amount of vanadyl acetylacetonate in an agate mortar and subsequently calcined at $500{ }^{\circ} \mathrm{C}$ for $4 \mathrm{~h}$. Each calcination step was performed in a quartz rotary furnace under $50 \mathrm{~mL} / \mathrm{min}$ flow of synthetic air (20\% $\left.\mathrm{O}_{2} / \mathrm{Ar}\right)$.

Raman measurements were performed using a Horiba-JobinYvon confocal LABRAM Raman microscope utilizing a $633 \mathrm{~nm}$ excitation source (HeNe laser). All samples were compressed into $7 \mathrm{~mm}$ diameter pellets using a hand press (PIKE Technologies) before being dehydrated in a purpose-built quartz cell. The cell was located in a tubular furnace (HTM Reetz, LOBA vertikal) where the sample was exposed to $20 \mathrm{vol} . \% \mathrm{O}_{2}$ in $\mathrm{N}_{2}$ (total flow $50 \mathrm{~mL}$ / $\min$ ) at $723 \mathrm{~K}$ for $1 \mathrm{~h}$. The cell was then isolated and mounted on the microscope stage where spectra were collected with a laser power of $1.5 \mathrm{~mW}$. UV-visible diffuse reflectance spectra (UV-vis 
DRS) were recorded using a PerkinElmer Lambda 650 spectrometer equipped with a Harrick Praying Mantis ${ }^{\mathrm{TM}}$ diffuse reflectance attachment (DRP-P72) and reaction chamber (HVC-VUV), operating under flow conditions. UV-visible spectra were measured in the $200-800 \mathrm{~nm}$ range. $20-30 \mathrm{mg}$ of the powdered material was necessary to fill the sample cup of the in situ cell. Reflectance measurements were converted to absorption spectra using the Kubelka-Munk function $\left(F\left(R_{\infty}\right)\right)$ [25]. All spectra are referenced against SBA-15, which was used as white standard. All samples were diluted (5-fold) in SBA-15 and dehydrated at $723 \mathrm{~K}$ in flowing synthetic air for 60 min prior to collecting spectra at room temperature. All spectra are normalized between zero and unity. The spectrum of $\mathrm{Al}_{2} \mathrm{O}_{3}$ support has, in addition, been linearly scaled, so that the intensity at $600 \mathrm{~nm}$ is near zero. Alumina is an effective "white standard" and without this additional procedure, the intensity of minority species (and noise) would otherwise be artificially enhanced as a consequence of the normalization procedure. For purposes of qualitative comparison between catalyst and support, this procedure seems suitable since neither dispersed vanadia, $\mathrm{V}_{2} \mathrm{O}_{5}$ agglomerates, nor $\mathrm{Al}_{2} \mathrm{O}_{3}$ are reported to have a strong absorbance in this region of the spectrum.

Nitrogen adsorption isotherms were measured by a Micromeritics Gemini 2375 surface analyzer. The surface area is calculated by the method of Brunauer, Emmitt, and Teller (BET) and the pore size distribution by the method of Barrett, Joyner, and Halenda (BJH). For elementary analysis, a Varian ICP-OES 715-ES is used. The samples were solubilized in a CEM microwave AD 1058 in a mixture of one part hydrochloric acid, three parts nitric acid and two parts sulfuric acid at $200{ }^{\circ} \mathrm{C}$ for a period of $25 \mathrm{~min}$. Temperature-programmed reduction (TPR) measurements were performed in a quartz reactor. Catalyst samples were fully oxidized with synthetic air at $500{ }^{\circ} \mathrm{C}$ for one hour and subsequently cooled to room temperature. The sample was then quenched in helium before the gas stream was switched to $3 \%$ ethanol in helium at $30 \mathrm{~N} \mathrm{~mL} / \mathrm{min}$, and the catalyst was heated to $250{ }^{\circ} \mathrm{C}$ at heating rate of $2 \mathrm{~K} / \mathrm{min}$. Evolved acetaldehyde was measured by a quadrupole mass spectrometer (InProcess Instruments) as a function of time.

The defect formation enthalpies of oxygen vacancies were determined using temperature-dependent conductivity experiments. The method is described in detail in [26]. On heating an enthalpy $\Delta H^{*}$ that comprises a term for defect formation $\Delta H_{f}$ and charge carrier migration $\Delta H_{m}$ is measured:

$\Delta H^{*}=\Delta H_{m}+1 / 3 \Delta H_{f}$

Then, on cooling only the migration enthalpy is determined. For pure vanadia, this is already achieved in an oxygen environment due to slow re-equilibration kinetics. However, the supported catalysts reestablish the equilibrium state on cooling in oxygen, and therefore, the experiments are done in nitrogen. Thus, by knowing the migration enthalpy, $\Delta H_{m}$, and apparent enthalpy, $\Delta H^{*}$, the defect formation enthalpy, $\Delta H_{f}$, for oxygen vacancies can be calculated.

For the impedance spectroscopic experiments, compressed powder disks with a diameter of $6 \mathrm{~mm}$ and a thickness of $2 \mathrm{~mm}$ were prepared. Platinum electrodes with a diameter of $5 \mathrm{~mm}$ were sputter coated on both sides with an Ar-plasma for proper electronic contact. The samples were oxidized in a tubular furnace under flowing oxygen at $500{ }^{\circ} \mathrm{C}$ for $4 \mathrm{~h}$. The disks were then cooled to $>100^{\circ} \mathrm{C}$ and placed in a desiccator to minimize water adsorption. The impedance spectroscopic experiments (impedance analyser: Zahner, IM6ex) were performed in a nitrogen atmosphere in the temperature range $400-500{ }^{\circ} \mathrm{C}$ with a heating and cooling rate of $0.1 \mathrm{~K} / \mathrm{min}$. A bandwidth of $7 \mathrm{mHz}-1 \mathrm{kHz}$ with an amplitude of $50 \mathrm{mV}$ was applied. For the calculation of the conductivity, the resistance attributed to the bulk relaxation was used. The impedance spectra were analyzed using the software Thales v1.X(Zahner).
The catalytic tests for ethanol oxidation were performed in a stainless steel fixed-bed reactor system with an inner diameter of $8 \mathrm{~mm}$. The reactor tubes are coated with a SilcoTek ${ }^{\mathrm{TM}}$ silicon coating to prevent catalytic activity and coke formation on the reactor walls. Kinetic measurements were performed under differential conditions with a standard stoichiometric feed composition of $6 \mathrm{kPa}$ oxygen and $12 \mathrm{kPa}$ ethanol at an overall flow rate of $220 \mathrm{~N} \mathrm{~mL} / \mathrm{min}$. The investigated temperature interval was between $140{ }^{\circ} \mathrm{C}$ and $200{ }^{\circ} \mathrm{C}$. The product stream was analyzed by a Shimadzu GC-2014 equipped with a methanizer, thermal conductivity detector, flame ionization detector, and packed HayeSep Q and Molsieve 13X columns. Experimental setup for propane oxidation is described elsewhere [3].

\section{Results}

\subsection{Powder catalysts}

\subsubsection{ICP-OES and BET}

Table 1 shows the surface areas, the loading of vanadia and the resulting surface density of vanadium on the supports. Vanadium surface densities were calculated from the concentration of vanadium in the sample by assuming a uniform dispersion over the entire surface of the support. One can see that the surface densities of vanadium on all supports are around 3.5 atoms per square nanometer, which is approximately half of a monolayer coverage of polymeric vanadyl species and 1.5 times higher than the theoretical monolayer of monomeric vanadyl species [27,28]. Only marginal reductions in both surface area and pore volume over the entire pore size distribution were observed after the thermal spreading and calcination treatment.

\subsubsection{Raman and UV-vis}

The positions of charge transfer bands in UV/vis spectra of vanadium oxide species have been correlated with specific electronic transitions. For example, bands with absorption edges in the range 310-620 nm have been attributed to $\mathrm{O}^{2-} \rightarrow \mathrm{V}^{5+}$, while bands with absorption edges in the range ca. 250-275 have been assigned to $\mathrm{O}^{2-} \rightarrow \mathrm{V}^{4+}$ transitions [29-31]. For semiconductors, the positions of absorption maxima have been attributed to an increase in domain size [32-35]. This methodology has been applied to the study of vanadia supported on several metal oxide materials, including alumina [36]; silica [37]; zirconia [7]; and titania [38].

With reference to model catalysts, isolated tetrahedrally coordinated monovanadate ions are reported to absorb at ca. 240 and $290 \mathrm{~nm}$ [39], while polyvanadate ions with octahedral/pentahedral coordination present absorption features located at 270,340, and $412 \mathrm{~nm}$ [40]. Examination of Fig. 1a reveals that crystalline $\mathrm{V}_{2} \mathrm{O}_{5}$ presents a very broad absorption feature with maxima located at 440 and $490 \mathrm{~nm}$.

Fig. 1 presents diffuse reflectance UV/vis spectra of supported vanadium oxide catalysts and associated with support materials. Examination of the spectra clearly shows that $\mathrm{CeO}_{2}, \mathrm{TiO}_{2}$, and $\mathrm{ZrO}_{2}$ supports absorb strongly in the range $200-400 \mathrm{~nm}$. It is not possible to identify very highly dispersed vanadium oxide species on these samples since absorptions due to such species are dwarfed

Table 1

Physical properties of the catalysts.

\begin{tabular}{llll}
\hline Support & Surface area $\left(\mathrm{m}^{2} / \mathrm{g}\right)$ & Surface density $\left(\mathrm{V}\right.$ atoms $\left./ \mathrm{nm}^{2}\right)$ & wt.\% V \\
\hline $\mathrm{TiO}_{2}$ & 17.1 & 3.5 & 0.6 \\
$\mathrm{Al}_{2} \mathrm{O}_{3}$ & 200.9 & 3.1 & 4.9 \\
$\mathrm{ZrO}_{2}$ & 52.1 & 3.1 & 1.4 \\
$\mathrm{CeO}_{2}$ & 19.8 & 3.9 & 0.7 \\
\hline
\end{tabular}




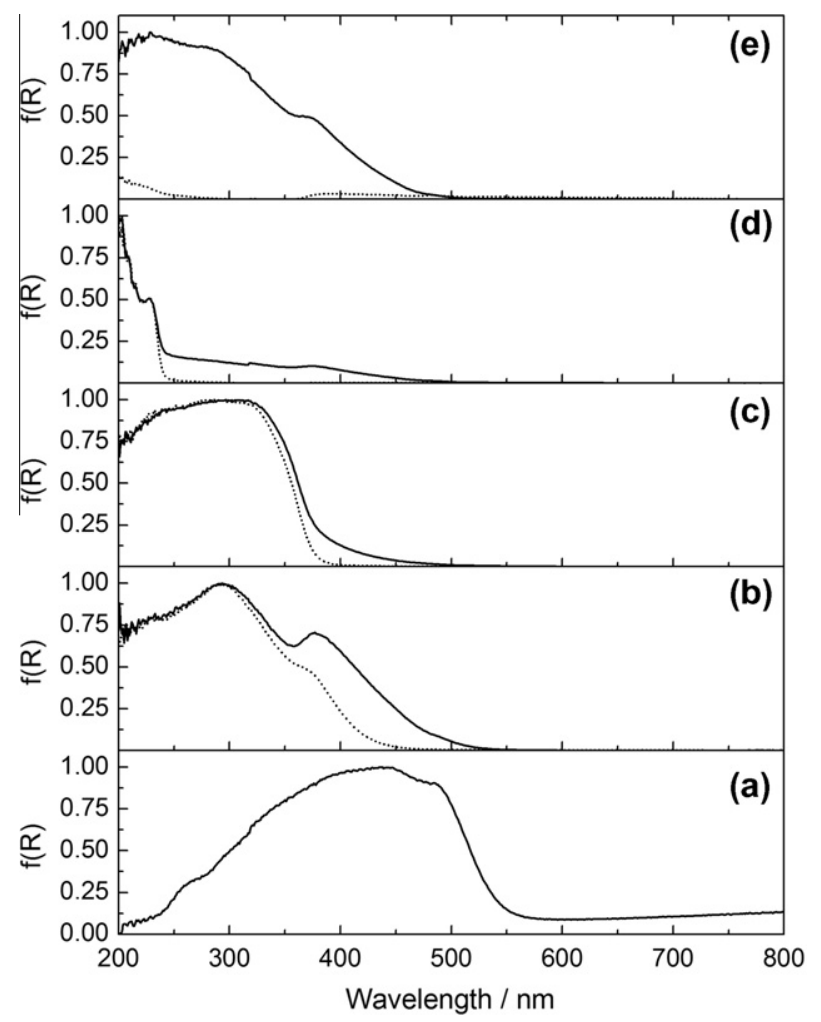

Fig. 1. Diffuse reflectance UV-vis spectra for a series of catalysts and associated supports recorded in situ after dehydration at $723 \mathrm{~K}$ in synthetic air. Dotted lines represent support materials, while catalyst samples are represented by a solid line. (a) $\mathrm{V}_{2} \mathrm{O}_{5}$; (b) $\mathrm{VO}_{x} / \mathrm{CeO}_{2}$ and $\mathrm{CeO}_{2}$; (c) $\mathrm{VO}_{x} / \mathrm{TiO}_{2}$ and $\mathrm{TiO}_{2}$; (d) $\mathrm{VO}_{x} / \mathrm{ZrO}_{2}$ and $\mathrm{ZrO}_{2}$; (e) $\mathrm{VO}_{x} / \mathrm{Al}_{2} \mathrm{O}_{3}$ and $\mathrm{Al}_{2} \mathrm{O}_{3}$.

by the intense charge transfer bands associated with the support material. However, for the spectrum of $\mathrm{VO}_{x} / \mathrm{Al}_{2} \mathrm{O}_{3}$ (Fig. 1e), which exhibits minimal contributions from the support material, broad and overlapping maxima are observed at 232, 280, and $370 \mathrm{~nm}$. The features located at 232 and $280 \mathrm{~nm}$ have previously been attributed to isolated vanadia sites and oligomeric $\mathrm{V}-\mathrm{O}-\mathrm{V}$ species, respectively [41], while the $370 \mathrm{~nm}$ feature has been assigned to polymerized $\mathrm{VO}_{6}$ species [42]. None of the catalysts examined here present significant absorption at $490 \mathrm{~nm}$, which, in comparison with Fig. 1a, would indicate the presence of three-dimensional $\mathrm{V}_{2} \mathrm{O}_{5}$ crystallites. Rather, the data indicate that all catalyst samples contain polymeric vanadia species, while we cannot discount the presence of additional highly dispersed monomeric vanadia species due to overlapping support absorptions at low wavelengths. We note that the spectrum of $\mathrm{VO}_{x} / \mathrm{CeO}_{2}$ exhibits a maximum located at ca. $380 \mathrm{~nm}$, indicating the presence of polymerized $\mathrm{VO}_{6}$ species. The persistence of a broad "tail" that exhibits residual intensity at $490 \mathrm{~nm}$ indicates that additional vanadia species that are more agglomerated than those found in the other catalyst samples are also present. That this is observed only for the $\mathrm{VO}_{x} / \mathrm{CeO}_{2}$ sample is could be a consequence of its higher vanadium surface density compared with the other catalysts in the series. However, we draw attention to the fact that stoichiometric crystalline $\mathrm{V}_{2} \mathrm{O}_{5}$ yields an optical band gap edge energy of ca. $563 \mathrm{~nm}$, corresponding to the $\mathrm{O}^{2-} \rightarrow \mathrm{V}^{5+}$ charge transfer in an infinite array of pseudo-octahedral vanadium ions [43], that is not observed in any of the catalyst samples measured here. So, although we are unable to make a detailed characterization of the of the supported vanadia species (due to prohibitively strong support absorptions in the region 200-390 nm), we can reject the presence of three-dimensional crystalline $\mathrm{V}_{2} \mathrm{O}_{5}$ species from the catalyst samples considered in the present study.
Raman spectroscopy was applied to further characterize the catalysts and, crucially, to confirm the absence of $\mathrm{V}_{2} \mathrm{O}_{5}$ nano-crystallites. Fig. 2A presents Raman spectra of several supported vanadia catalysts in the energy range $120-1200 \mathrm{~cm}^{-1}$. With the exception of $\mathrm{VO}_{x} / \mathrm{Al}_{2} \mathrm{O}_{3}$, the spectra are dominated by vibrational modes associated with the support materials. For $\mathrm{VO}_{x} / \mathrm{CeO}_{2}$ (Fig. 2A-ii), the intense signal located at $463 \mathrm{~cm}^{-1}$ corresponds to the first-order-allowed, triply degenerate $\mathrm{F}_{2 \mathrm{~g}}$ mode Raman line of crystalline $\mathrm{CeO}_{2}$. The FWHM of $8.7 \mathrm{~cm}^{-1}$ reflects the high crystallinity of the $\mathrm{CeO}_{2}$ support [44]. $\mathrm{VO}_{x} / \mathrm{TiO}_{2}$ (Fig. 2A-iii) is dominated by signals located at $142,195,393,514$, and $636 \mathrm{~cm}^{-1}$, which are respectively assigned to $E_{g}, E_{g}, B_{1 g}, A_{1 g}$ (or $B_{1 g}$ ), and $E_{g}$ modes of $\mathrm{TiO}_{2}$ in the anatase phase. There is no indication of a secondary rutile phase, which would yield signals at 232,449 , and $612 \mathrm{~cm}^{-1}$. $\mathrm{VO}_{x} / \mathrm{ZrO}_{2}$ (Fig. 2A-iv) exhibits the most complex spectrum with features observed at 140,177, 189, 220, 305, 331, 345, 380, 474, $500,535,556,613$, and $634 \mathrm{~cm}^{-1}$. Raman spectra of monoclinic and tetragonal $\mathrm{ZrO}_{2}$ phases share many common signals, however, the signal located $140 \mathrm{~cm}^{-1}$ is peculiar only to the tetragonal phase, while the feature located at $345 \mathrm{~cm}^{-1}$ occurs only in monoclinic $\mathrm{ZrO}_{2}$ [45]. Thus, the Raman spectrum of $\mathrm{VO}_{x} / \mathrm{ZrO}_{2}$ indicates that a mixture of monoclinic and tetragonal $\mathrm{ZrO}_{2}$ phases is present. The spectrum of $\mathrm{VO}_{x} / \mathrm{Al}_{2} \mathrm{O}_{3}$ (Fig. 2A-v) presents broad signals located at ca. 257, 338, 490, and $601 \mathrm{~cm}^{-1}$, which we attribute to contributions from the cell window (silica). These features are more prominent in spectrum of $\mathrm{VO}_{x} / \mathrm{Al}_{2} \mathrm{O}_{3}$ compared with the other spectra due to the fact that $\mathrm{Al}_{2} \mathrm{O}_{3}$ is a poor Raman scatterer in comparison with the other support materials studied here.

The position of the $\mathrm{v}(\mathrm{V}=\mathrm{O})$ stretching band, which is located at $995 \mathrm{~cm}^{-1}$ in pure $\mathrm{V}_{2} \mathrm{O}_{5}$ [46], has been widely related to supported vanadia clusters of varying nuclearity [47-55]. With respect to the catalysts studied here, $\mathrm{VO}_{x} / \mathrm{CeO}_{2}$ (Fig. $2 \mathrm{~B}$-ii) presents the most structured $\mathrm{v}(\mathrm{V}=\mathrm{O})$ envelope. The observation of several discrete $\mathrm{V}=\mathrm{O}$ stretching modes suggests the presence of several different supported vanadia structures. With signals located at 1021, 1028, and $1043 \mathrm{~cm}^{-1}$, the spectrum of $\mathrm{VO}_{x} / \mathrm{CeO}_{2}$, which has a vanadium surface density of 3.9 atoms $/ \mathrm{nm}^{2}$, is in very good agreement with that previously reported for a $\mathrm{VO}_{x} / \mathrm{CeO}_{2}$ sample with a calculated surface density of 5 atoms $/ \mathrm{nm}^{2}$ [47]. Bands located at 1022 , 1030 , and $1044 \mathrm{~cm}^{-1}$ were tentatively assigned to $\mathrm{V}=\mathrm{O}$ stretching modes associated with dimeric, trimeric and polymeric vanadia species, respectively. A fourth band located at $1008 \mathrm{~cm}^{-1}$, which is not observed in the spectrum of our $\mathrm{VO}_{x} / \mathrm{CeO}_{2}$ sample, was

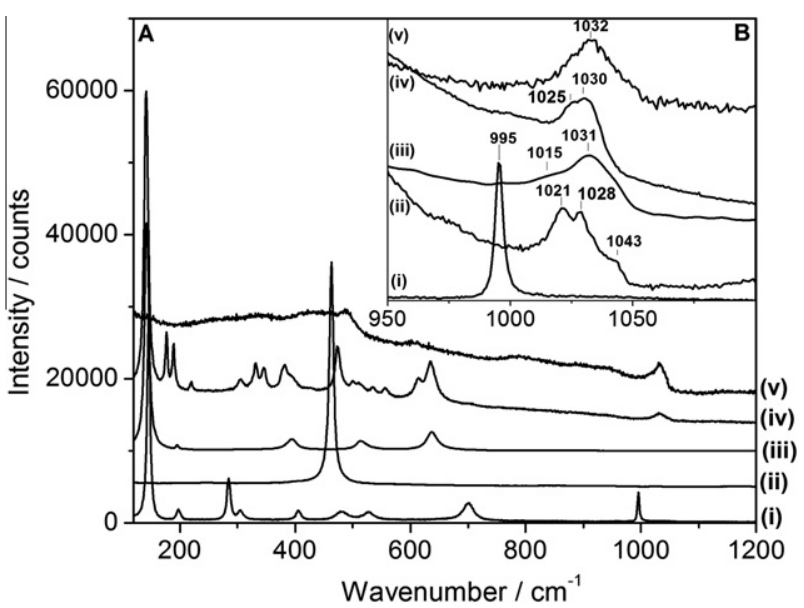

Fig. 2. (A) Raman spectra of (i) $\mathrm{V}_{2} \mathrm{O}_{5}$; (ii) $\mathrm{V} / \mathrm{CeO}_{2}$; (iii) $\mathrm{V} / \mathrm{TiO}_{2}$; (iv) $\mathrm{V} / \mathrm{ZrO}_{2}$; (v) $\mathrm{V} /$ $\mathrm{Al}_{2} \mathrm{O}_{3}$ samples in the energy range $120-1200 \mathrm{~cm}^{-1}$. (B) Second measurement of the same sample series in the energy range $900-1100 \mathrm{~cm}^{-1}$. The spectra presented in (B) have been normalized to facilitate comparison. 
assigned to monomeric vanadia species. These assignments were based on the results of Baron et al. [48] who used a combination of STM imaging and surface infrared spectroscopy to examine $\mathrm{VO}_{x}$ clusters on a $\mathrm{CeO}_{2}(111)$ surface. The band observed at $930 \mathrm{~cm}^{-1}$ has been assigned to $\mathrm{V}-\mathrm{O}-\mathrm{V}$ stretching in polyvanadate $[49,56,57]$, while the broad background in the range 850$970 \mathrm{~cm}^{-1}$ has been assigned to various $\mathrm{V}-\mathrm{O}-\mathrm{Ce}$ modes $[23,49,56]$. The absence of obvious features located at 770 and $841 \mathrm{~cm}^{-1}$ indicates that $\mathrm{CeVO}_{4}$ is absent from the $\mathrm{VO}_{x} / \mathrm{CeO}_{2}$ sample [58]. The spectrum of $\mathrm{VO}_{x} / \mathrm{TiO}_{2}$ (Fig. 2B-iii) exhibits a feature located at $1030 \mathrm{~cm}^{-1}$ with a shoulder at $1025 \mathrm{~cm}^{-1}$. The appearance of two features indicates the presence of at least two discrete supported vanadia structures. The Raman spectrum of the $\mathrm{VO}_{x} / \mathrm{ZrO}_{2}$ sample (Fig. 2B-iv) exhibits a feature located at $1030 \mathrm{~cm}^{-1}$, which has previously been assigned as zirconia-supported polyvanadate species [50]. The broadness of this band may indicate that a number of different supported vanadia species coexist. The absence of signals located at 775 and $982 \mathrm{~cm}^{-1}$ indicates an absence of a $\mathrm{ZrV}_{2-}$ $\mathrm{O}_{7}$ phase. The spectrum of $\mathrm{VO}_{x} / \mathrm{Al}_{2} \mathrm{O}_{3}$ (Fig. 2-v) presents a broad feature located at $1031 \mathrm{~cm}^{-1}$ with a low frequency shoulder at $1015 \mathrm{~cm}^{-1}$, suggesting the presence of more than one vanadia species. The presence of an additional weak shoulder located at ca. $995 \mathrm{~cm}^{-1}$ indicates that $\mathrm{V}_{2} \mathrm{O}_{5}$ crystallites could also be present. However, since $\mathrm{V}_{2} \mathrm{O}_{5}$ is reported to have a Raman scattering cross section that is one order of magnitude greater than dispersed vanadium oxide species [59], we deduce that it is exceedingly low concentration.

Based on previous work [60-62], Busca [63] affirms that the surface metal vanadyl species formed at low loading on different metal oxide supports (alumina, titania, zirconia, and ceria) are similar, and that the position of the $\mathrm{V}=\mathrm{O}$ stretching wave number is only weakly dependent on the support, and that the surface coverage is more critical, being slightly shifted upwards on increasing the vanadium loading $[64,65]$. The position of the $V=0$ has been variously related to the nuclearity of supported vanadia clusters. The frequency of the $\mathrm{V}=\mathrm{O}$ oscillator has been shown to follow the ranking polymerized vanadia $>$ isolated vanadia $>\mathrm{V}_{2} \mathrm{O}_{5}[50-$ 53]. The increase in $\mathrm{V}=\mathrm{O}$ stretching frequency has been interpreted as being due to increased dipole-dipole coupling between $\mathrm{V}=\mathrm{O}$ oscillators in vanadia species with higher degrees of polymerization [47]. However, it has also been reported that the $V=0$ stretching frequency follows the ranking isolated vanadia $>$ polymerized vanadia $>\mathrm{V}_{2} \mathrm{O}_{5}$ [51]. This lack of consistency in the assignment of bands to particular cluster formations is particularly evident when comparing vanadia deposited on different support materials. For example, a Raman signal located at $1042 \mathrm{~cm}^{-1}$ is assigned to monomeric vanadia species in $\mathrm{VO}_{x} / \mathrm{SiO}_{2}$, while on $\mathrm{VO}_{x} / \mathrm{CeO}_{2}$, a features at similar energies $\left(1044 \mathrm{~cm}^{-1}\right.$ [47] and $1040 \mathrm{~cm}^{-1}$ [48]) have previously been assigned to polymeric $\mathrm{VO}_{x}$ species. In contrast, signals observed at $1043 \mathrm{~cm}^{-1}$ in the Raman spectra of a $\mathrm{VO}_{x} / \mathrm{CeO}_{2}(111)$ model system have been assigned to monomeric species based on comparison with scanning tunneling microscope images [48]. In addition, bands located at $1042 \mathrm{~cm}^{-1}$ for $\mathrm{VO}_{x} / \mathrm{SiO}_{2}$ samples [54,55] have been assigned to monomeric $\mathrm{VO}_{x}$ species based on a comparison with trihalovanadyl complexes [66,67].

A combined DFT and multi-wavelength Raman spectroscopic investigation revealed that the fundamental $\mathrm{V}=\mathrm{O}$ stretching mode of $\mathrm{VO}_{x}$ clusters supported on silica is strongly coupled to vanadiasilica interface modes and that shifts in the position of this band cannot simply be interpreted as being due to a change in the bond strength and bond length of the vanadium oxygen double bond [68]. Treatment of the vanadyl stretching band as an isolated species that is independent of support vibrations, as is the case in the vast majority of the literature, is an oversimplification that may lead to erroneous results. It has been clearly shown that interface modes between vanadia and the support must be considered in order to assign spectral features to isolated and polymeric species [68]. In the absence of a universally accepted assignment of supported vanadia species based purely on the vanadyl stretching frequency, we refrain from making a precise statement regarding the structures of the supported vanadia species on the catalysts examined here. However, we can say with certainty that the surface of these samples is dominated by dispersed vanadia species with various degrees of nuclearity and/or local environment as reflected by the broad (and sometimes multistructured) $\mathrm{V}=\mathrm{O}$ stretching bands observed by Raman spectroscopy. This assertion is supported by diffuse reflectance UV/vis measurements that show broad features exhibiting intensity over a wide energy range that incorporates vanadia species of varyingly nuclearity. Crucially, the presence of $\mathrm{V}_{2} \mathrm{O}_{5}$ can be excluded from all but the $\mathrm{VO}_{x} / \mathrm{Al}_{2} \mathrm{O}_{3}$ sample, which contains trace amounts at most. As a conclusion of the catalyst characterization, we assume to have a set of catalysts with similar vanadia surface species that allow an identification and discussion of the support effects on the catalytic activity.

\subsubsection{Temperature-programmed reduction}

Fig. 3 shows the temperature dependency of acetaldehyde evolution for the different supported catalysts when ethanol is employed as the reductant. For vanadia supported on titania, zirconia, and ceria, one product desorption peak can be observed. Vanadia supported on alumina gives two acetaldehyde evolution peaks. However, dehydration of ethanol commences at temperatures higher than $200^{\circ} \mathrm{C}$, producing ethylene, which also has a primary mass peak at $28 \mathrm{~m} / \mathrm{z}$ and therefore compromises the MS measurement due to overlap with the acetaldehyde mass spectra. In the case of vanadia/alumina, this phenomenon strongly overlaps with the product desorption peaks. Integration of the acetaldehyde signal indicates an approximate reduction in vanadium from oxidation state $\mathrm{V}$ to IV for the different catalysts, which supports the aforementioned model. Comparison of the peak maxima gives the ranking for the reactivity of $\mathrm{VO}_{x} / \mathrm{TiO}_{2}>\mathrm{VO}_{x} / \mathrm{ZrO}_{2}>\mathrm{VO}_{x} / \mathrm{CeO}_{2}>$ $\mathrm{VO}_{x} / \mathrm{Al}_{2} \mathrm{O}_{3}$. When using $\mathrm{H}_{2}$ as reductant, a different ranking of reactivity is observed, which is $\mathrm{VO}_{x} / \mathrm{ZrO}_{2}>\mathrm{VO}_{x} / \mathrm{TiO}_{2}>\mathrm{VO}_{x} / \mathrm{Al}_{2} \mathrm{O}_{3}>\mathrm{VO}_{x} \mid$ $\mathrm{CeO}_{2}$. Integration of consumed hydrogen indicates a reduction from oxidation state $\mathrm{V}$ to III. The TPR results are very similar to other reported studies [3,8]. Table 2 summarizes the TPR peak maxima for both reductants ethanol and hydrogen.

\subsubsection{Impedance spectroscopy}

Table 3 depicts the defect formation enthalpies determined according to the method described in $[26,69]$ for the supported vanadia catalysts. Following ranking of defect formation is found: $\mathrm{VO}_{x} / \mathrm{TiO}_{2}<\mathrm{VO}_{x} / \mathrm{ZrO}_{2}<\mathrm{VO}_{x} / \mathrm{CeO}_{2}<\mathrm{VO}_{x} / \mathrm{Al}_{2} \mathrm{O}_{3}$. Reference values are

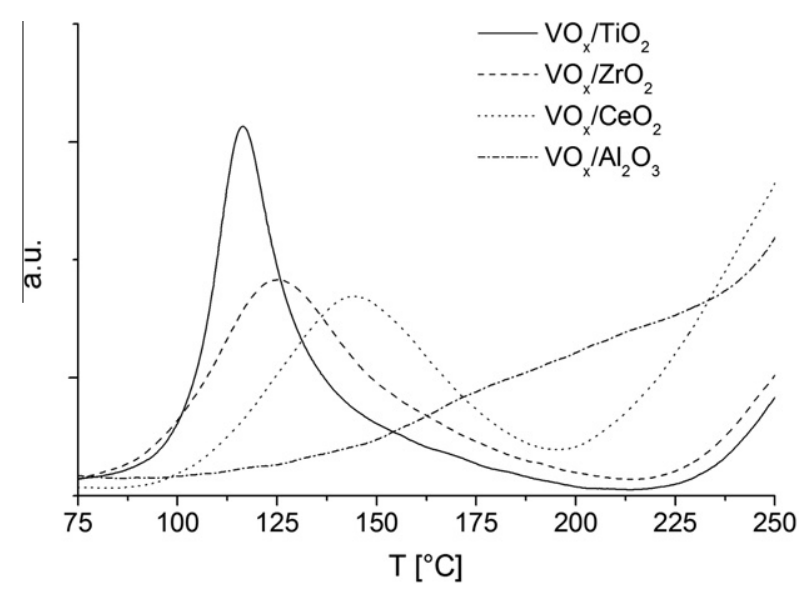

Fig. 3. EtOH-TPR with a heating rate of $2 \mathrm{~K} / \mathrm{min}$ and $3 \mathrm{~mol} \% \mathrm{EtOH}$. 
Table 2

TPR and TPD peak maxima.

\begin{tabular}{lllll}
\hline Catalyst & $\begin{array}{l}\mathrm{VO}_{x} / \mathrm{Al}_{2} \mathrm{O}_{3} \\
\left({ }^{\circ} \mathrm{C}\right)\end{array}$ & $\begin{array}{l}\mathrm{VO}_{x} / \mathrm{CeO}_{2} \\
\left({ }^{\circ} \mathrm{C}\right)\end{array}$ & $\begin{array}{l}\mathrm{VO}_{x} / \mathrm{ZrO}_{2} \\
\left({ }^{\circ} \mathrm{C}\right)\end{array}$ & $\begin{array}{l}\mathrm{VO}_{x} / \mathrm{TiO}_{2} \\
\left({ }^{\circ} \mathrm{C}\right)\end{array}$ \\
\hline $\mathrm{H}_{2}$-TPR max. & 425 & 437 & 357 & 399 \\
EtOH-TPR max. & 175 & 145 & 125 & 116 \\
\hline
\end{tabular}

Table 3

Oxygen defect formation enthalpies of supported vanadia catalysts.

\begin{tabular}{llllll}
\hline Catalst & $\mathrm{VO}_{x} / \mathrm{Al}_{2} \mathrm{O}_{3}$ & $\mathrm{~V}_{2} \mathrm{O}_{5}$ & $\mathrm{VO}_{x} / \mathrm{CeO}_{2}$ & $\mathrm{VO}_{x} / \mathrm{ZrO}_{2}$ & $\mathrm{VO}_{x} / \mathrm{TiO}_{2}$ \\
\hline$\Delta H_{f}(\mathrm{~kJ} / \mathrm{mol})$ & 111 & 119 & 58 & 83 & 44 \\
\hline
\end{tabular}

available for pure $\mathrm{V}_{2} \mathrm{O}_{5}$, which are in good agreement with our experiments $(119 \mathrm{~kJ} / \mathrm{mol})$. Measurements on molten vanadia gave an enthalpy of $125 \mathrm{~kJ} / \mathrm{mol}$ [70], close to the result of DFT calculations for crystalline $\mathrm{V}_{2} \mathrm{O}_{5}, 113 \mathrm{~kJ} / \mathrm{mol}$ [13]. Therefore, the results for the supported catalysts may yield equal accuracy.

\subsubsection{Catalytic activity}

The presumable kinetics of the ethanol oxidation to acetaldehyde can be interpreted as a sequence of elementary steps as shown in Fig. 4(I). The catalytic cycle begins with the catalyst in an oxidized state. DFT calculations for the methanol oxidation [12] have shown that the alcohol first adsorbs dissociatively resulting in a cleavage of a $\mathrm{V}-\mathrm{O}-\mathrm{S}$ ( $\mathrm{S}=$ support) or $\mathrm{V}-\mathrm{O}-\mathrm{V}$ bond.

We note that in the case of the vanadia/ceria system, it is reasonable to assume that adsorption of ethanol may also occur on the support in close proximity to the $\mathrm{V}=\mathrm{O}$ moiety instead directly on the vanadyl site. In the consecutive step, a hydrogen atom is transferred from the ethoxide species to the vanadyl oxygen atom, which creates kind of biradical structure with one unpaired electron at the ${ }^{\circ} \mathrm{C}_{2} \mathrm{H}_{4} \mathrm{O}$ - group and the other in vanadium d-states. Acetaldehyde is formed when the ${ }^{\cdot} \mathrm{C}_{2} \mathrm{H}_{4} \mathrm{O}-\mathrm{V}$ bond splits, and a second electron goes into vanadium d-states, either at the same $\mathrm{V}$ site or at a neighboring one. DFT calculations indicate that a pair of two vanadium (IV) is more stable than a $\mathrm{V}(\mathrm{V})$ and $\mathrm{V}(\mathrm{III})$ pairing [11,71]. Subsequently, water desorbs, either after recombination of two $\mathrm{V}(\mathrm{IV})-\mathrm{OH}$ groups or directly from the $\mathrm{V}(\mathrm{III})$ site. The irreversibility of this step is proven by the absence of inhibition by water [2]. The catalytic cycle is finally closed by oxidizing the two V(IV) sites or the V(III) site via irreversible chemisorption of oxygen to form the active site [2,71].

Based on a pseudo-steady state approach of the elementary steps detailed in Fig. 4 the following rate equation is derived:

$r=\frac{k_{2} K_{1} p_{\mathrm{C}_{2} \mathrm{H}_{5} \mathrm{OH}}^{\frac{1}{n}}}{1+K_{1} p_{\mathrm{C}_{2} \mathrm{H}_{5} \mathrm{OH}}^{\frac{1}{n}}+\frac{k_{2} K_{1} p_{\mathrm{C}_{2} \mathrm{H}_{5} \mathrm{OH}}^{\frac{1}{n}}}{k_{3} p_{\mathrm{O}_{2}}^{\frac{1}{2}}}} \approx k_{2}$

Here, $K_{1}$ is the equilibrium constant of the adsorption step, $k_{2}$ is the rate constant of the rate-limiting step, $k_{3}$ is the rate constant for the reoxidation, and $n$ is the constant for Freundlich adsorption isotherm. Because, at our reaction conditions, very fast reoxidation can be assumed [2], $k_{2} / k_{3}\left(p_{\mathrm{O} 2}\right)^{1 / 2} \ll 1$, the rate is approximately equal to $k_{2}$.

The ODH rate at steady state conditions is calculated at ethanol conversions of less than $10 \%$, that is, differential reaction conditions, by division of the acetaldehyde (AA) molar flow rate by the amount of vanadium atoms in the catalyst. This refers to the turnover frequency, if assuming every vanadium atom contributes equally to the reaction. The product distribution for all catalysts was almost independent of the temperature. Ceria-, zirconia-, and titania-supported vanadia catalysts exhibited a selectivity of greater than $98 \%$ to acetaldehyde with some diethylether as a byproduct and carbon oxides as consecutive reaction products, while alumina-supported vanadia a higher selectivity toward diethylether (15\%) was obtained, which is attributed to the Lewis or Brønsted acid sites present on the alumina support [72]. Table 4 shows that the $\mathrm{ODH}$ rates of the ethanol oxidation differ by almost

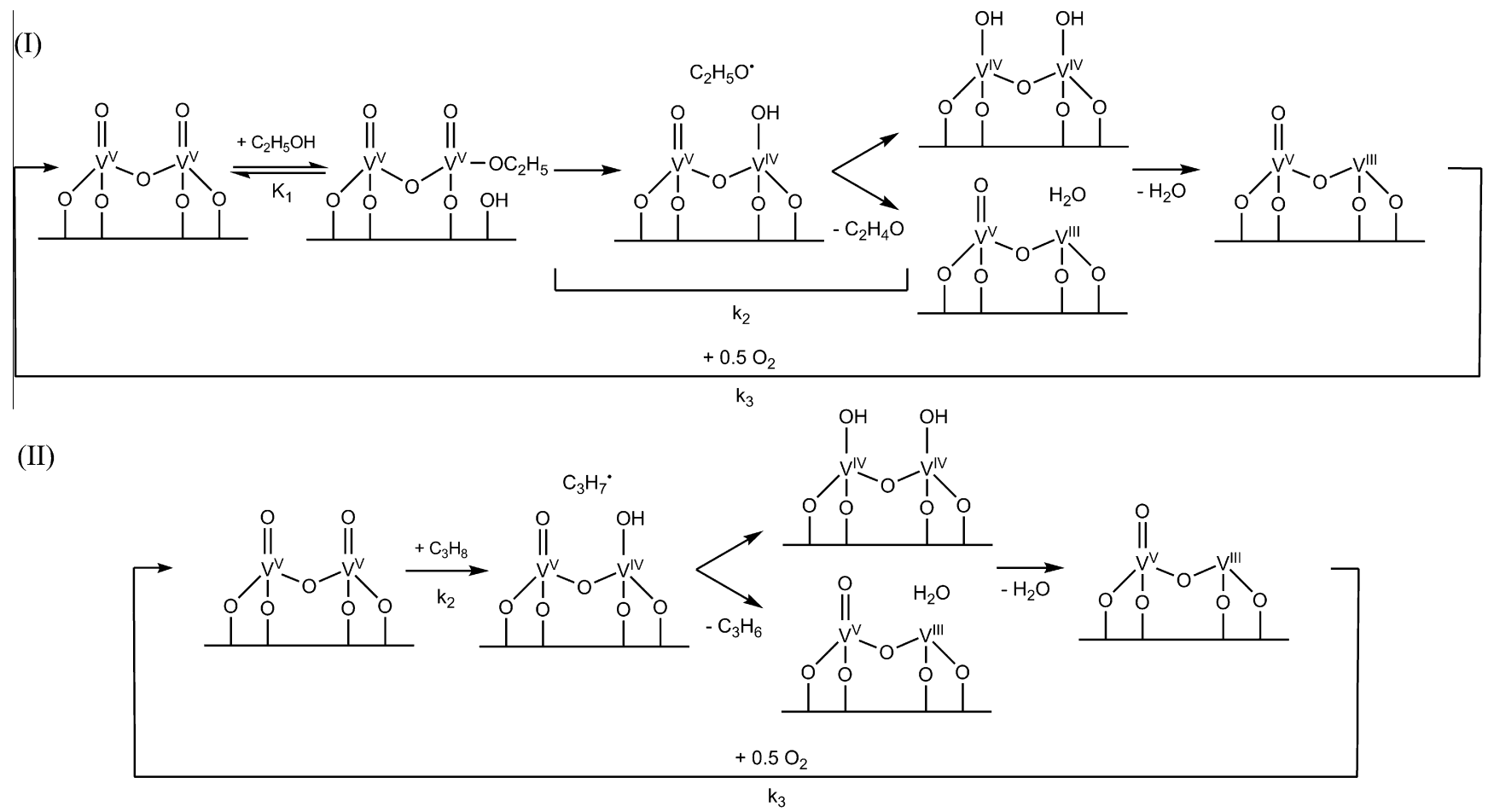

Fig. 4. Mechanistic model of the ODH of ethanol (I) and propane (II) on a dimeric vanadyl species. 
three orders of magnitude over all support materials with the ranking $\mathrm{VO}_{x} / \mathrm{Al}_{2} \mathrm{O}_{3} \ll \mathrm{V}_{2} \mathrm{O}_{5}<\mathrm{VO}_{x} / \mathrm{CeO}_{2}<\mathrm{VO}_{x} / \mathrm{ZrO}_{2} \ll \mathrm{VO}_{x} / \mathrm{TiO}_{2}$. Here, titania shows an outstanding performance. It must be noted that the apparent rate observed for $\mathrm{V}_{2} \mathrm{O}_{5}$ is erroneous due to the assumption of a surface density of 5 atoms $/ \mathrm{nm}^{2}$ and formation of volatile vanadyl ethoxides. The transformation of the surface and loss of catalyst leads to an underestimation of the observed ODH rate. The ethanol conversion over the pure support materials in this temperature range is negligible. Only bare ceria reveals high activity to total oxidation products at temperatures higher than $200^{\circ} \mathrm{C}$, which is suppressed by loading with vanadia as has been previously observed for different ODH reactions $[3,73]$ and additionally in model studies [70]. Dehydrogenation rates were measured as a function of temperature at all catalysts described above, and the apparent activation energies were derived from the resulting Arrhenius plots. The apparent activation energies and preexponential factors are presented in Table 4.

In order to find a relationship between the ODH of ethanol and propane as can be expected by the similar reaction mechanism (Fig. 4II), we investigated the same series of catalysts in the ODH of propane in the temperature range $400-500^{\circ} \mathrm{C}$. Calculation of the $\mathrm{ODH}$ rate is done under the assumption that no parallel reaction to carbon oxides takes place. This is justified by the high observed selectivity. The rate is obtained by division of the converted propane molar flow rate by the amount of vanadium atoms in the catalyst. The explicit values for the ODH rate, the apparent activation energies, and preexponential factors are given in Table 5.

Both reactions show the same reactivity ranking over the studied family of catalysts, although there is a significant change in the reaction temperature and the molecular structure of the two reactants. Pure vanadia has to be excluded. Due to formation of volatile vanadyl ethoxides, the ODH rate is erroneous as mentioned before.

In order to exclude influences of the catalyst morphology for two selected materials, thin-film model systems were studied at identical structure and conditions and modeled by DFT in order to quantify the obtained observations.

\subsection{Thin-film model catalysts}

The key experimental findings are presented in Fig. 5, from which a direct comparison of the vanadia/alumina and vanadia/ ceria systems may be made. For zirconia and titania thin-film model systems are not available, but fortunately, the two given systems represent boundary cases for our investigations into catalyst with strong support effects. We first address the results for vanadia/alumina. Deposition of vanadia onto an alumina film attenuates the alumina phonon band (located at $865 \mathrm{~cm}^{-1}$ ) and leads to the formation of $\mathrm{V}=\mathrm{O}$ terminated particles as evidenced by the appearance of the $\mathrm{V}=\mathrm{O}$ band at ca $1040 \mathrm{~cm}^{-1}$. Concomi- tantly, the presence of an interfacial $\mathrm{V}-\mathrm{O}-\mathrm{Al}$ mode, reported to be located at ca. $920 \mathrm{~cm}^{-1}$ [68], that overlaps with an alumina phonon results in a broadband centered at $900 \mathrm{~cm}^{-1}$. Based on the relationship between the morphology of vanadia species, observed by STM, and IRA spectra of the vanadia/alumina surfaces previously reported [22], we could estimate the vanadia coverage in these experiments, which is approximately 3 atoms $/ \mathrm{nm}^{2}$, respectively. The TPD spectra of ethanol adsorbed at $300 \mathrm{~K}$ on the respective vanadia/alumina surfaces did not show any detectable reactivity toward acetylaldehyde (AA) (see bottom left of Fig. 5).

In contrast, the vanadia/ceria system containing the same amount of vanadia showed substantial reactivity expressed as AA formation (right bottom in Fig. 5). The TPD spectra revealed two desorption features, that is, at $500 \mathrm{~K}$ and $\sim 600 \mathrm{~K}$. The high-temperature reactivity can straightforwardly be assigned to the reactivity of the bare ceria surface showing a similar TPD feature in the experiments performed with pristine ceria films (the dashed line). Obviously, the reactivity at $500 \mathrm{~K}$ must be associated with vanadia species. As we have recently shown [48], vanadia wets the ceria surface at sub-monolayer coverages and may form monomeric, oligomeric, or two-dimensional islands. These species can, in principle, be differentiated by IRAS based on the structure-frequency relationship observed for this system using scanning tunneling microscopy [48]: the higher the nuclearity of the vanadyl species, the higher the stretching frequency. The IRAS spectra of the vanadia/ceria samples (see top right panel in Fig. 5) suggest that di and trimeric as well as larger oligomeric species, showing the $1033 \mathrm{~cm}^{-1}$ band, dominate the surface. Therefore, the TPD and IRAS results on vanadia thin-film model catalysts clearly show the support effect such that vanadia supported on ceria is more active toward ethanol than vanadia supported on alumina.

\subsection{DFT results}

Fig. 6 compares oxygen defect formation for monomeric vanadia sites on $\mathrm{CeO}_{2}(111)$ and $\gamma-\mathrm{Al}_{2} \mathrm{O}_{3}(100)$. Whereas on the alumina surface, the vanadyl oxygen atom is removed providing the active site, on the ceria surface, the oxygen atom is removed from one of the $\mathrm{V}-\mathrm{O}-\mathrm{Ce}$ bridges. This assumption is supported by similar reactivity of incipient $\mathrm{CeVO}_{4}$ and dispersed vanadium oxide on ceria [74]. This results in a large relaxation effect for $\mathrm{VO}_{x} / \mathrm{CeO}_{2}$ and reduces the oxygen defect formation energy to $76 \mathrm{~kJ} / \mathrm{mol} \mathrm{com-}$ pared to $388 \mathrm{~kJ} / \mathrm{mol}$ for the $\mathrm{VO}_{x} /$ alumina sites. Without relaxation, the result for the ceria support $(385 \mathrm{~kJ} / \mathrm{mol})$ is very similar to that of the alumina support [23]. Fig. 6 also shows results for a dimeric vanadia species on $\gamma$-alumina, for which virtually the same oxygen defect formation energy is obtained. The much smaller oxygen defect formation energy for ceria as support compared to alumina explains the much higher reactivity toward ethanol oxidation observed in the thin-film experiments.

Table 4

ODH rates $\left(200^{\circ} \mathrm{C}\right)$, apparent activation energies and preexponential factors for the ODH of ethanol.

\begin{tabular}{|c|c|c|c|c|c|}
\hline Catalyst & $\mathrm{VO}_{x} / \mathrm{Al}_{2} \mathrm{O}_{3}$ & $\mathrm{~V}_{2} \mathrm{O}_{5}$ & $\mathrm{VO}_{x} / \mathrm{CeO}_{2}$ & $\mathrm{VO}_{x} / \mathrm{ZrO}_{2}$ & $\mathrm{VO}_{x} / \mathrm{TiO}_{2}$ \\
\hline $\mathrm{ODH}$ rates $\left(\mathrm{mol}_{\mathrm{AA}} / \mathrm{mol}_{\mathrm{V}} \mathrm{s}\right)$ & 0.006 & 0.055 & 0.088 & 0.11 & 0.41 \\
\hline$E_{a, a p p}(\mathrm{~kJ} / \mathrm{mol})$ & 91 & 77 & 72 & 80 & 66 \\
\hline$k_{\infty}\left(\mathrm{mol}_{\mathrm{AA}} / \mathrm{mol}_{\mathrm{V}} \mathrm{s}\right)$ & $7.15 \mathrm{E}+07$ & $1.52 \mathrm{E}+07$ & $1.77 \mathrm{E}+07$ & $9.26 \mathrm{E}+07$ & $1.09 \mathrm{E}+07$ \\
\hline
\end{tabular}

Table 5

ODH rates $\left(400^{\circ} \mathrm{C}\right)$, apparent activation energies and preexponential factors for the ODH of propane.

\begin{tabular}{|c|c|c|c|c|c|}
\hline Catalyst & $\mathrm{VO}_{x} / \mathrm{Al}_{2} \mathrm{O}_{3}$ & $\mathrm{~V}_{2} \mathrm{O}_{5}$ & $\mathrm{VO}_{x} / \mathrm{CeO}_{2}$ & $\mathrm{VO}_{x} / \mathrm{ZrO}_{2}$ & $\mathrm{VO}_{x} / \mathrm{TiO}_{2}$ \\
\hline ODH rates $\left(\mathrm{mol}_{\mathrm{C}_{3} \mathrm{H}_{6}} / \mathrm{mol}_{\mathrm{V}} \mathrm{s}\right)$ & 0.003 & 0.058 & 0.023 & 0.033 & 0.261 \\
\hline$E_{a, a p p}(\mathrm{~kJ} / \mathrm{mol})$ & 117 & 96 & 90 & 102 & 82 \\
\hline$k_{\infty}\left(\mathrm{mol}_{\mathrm{C}_{3} \mathrm{H}_{6}} / \mathrm{mol}_{\mathrm{V}} \mathrm{s}\right)$ & $3.74 \mathrm{E}+06$ & $1.67 \mathrm{E}+06$ & $2.24 \mathrm{E}+05$ & $2.56 \mathrm{E}+06$ & $5.42 \mathrm{E}+05$ \\
\hline
\end{tabular}



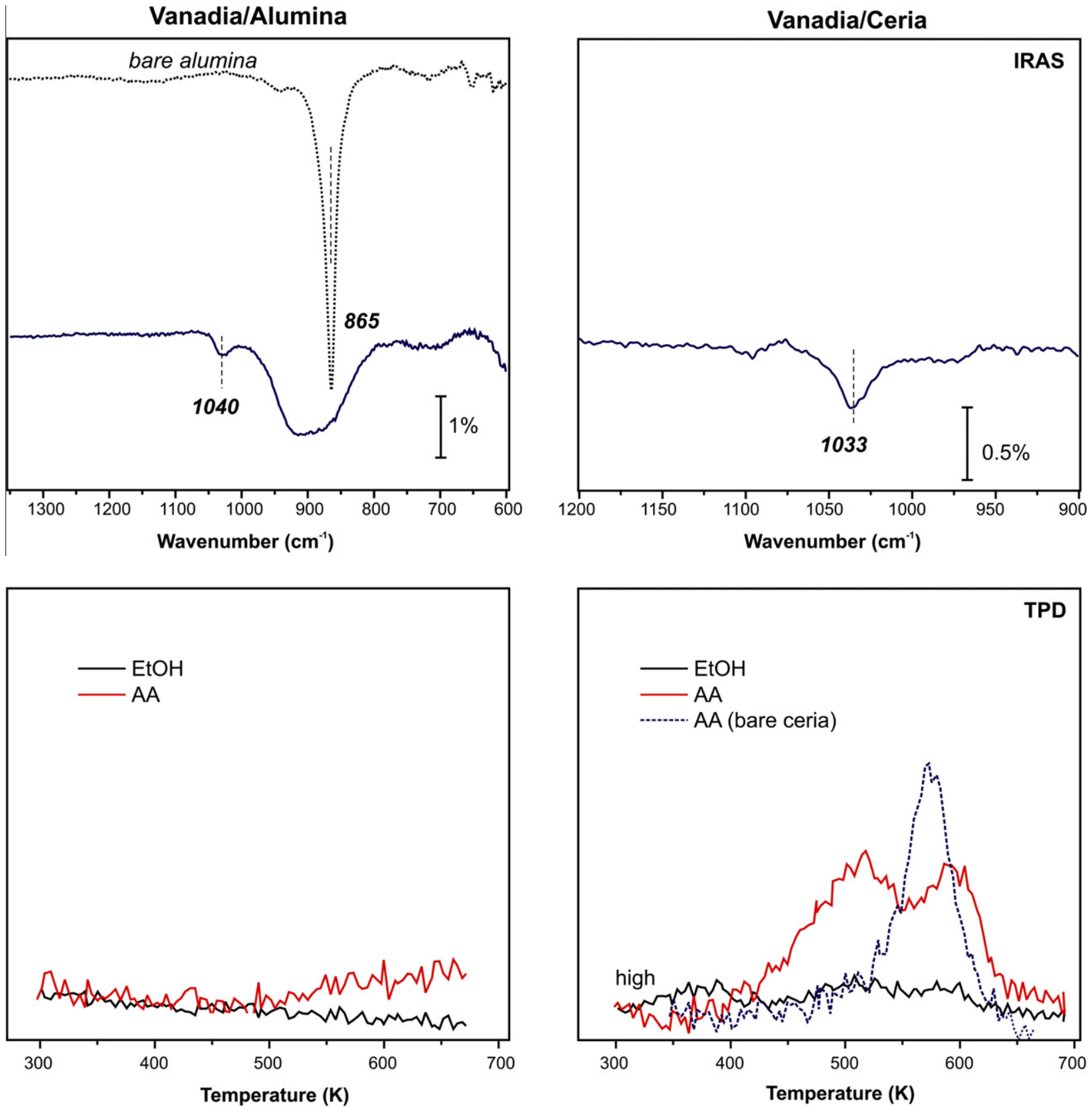

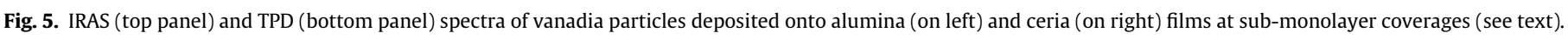

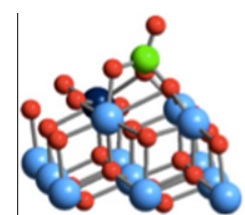

76 (PBE+U)

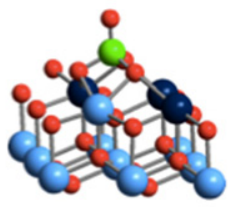

$\mathrm{VO}_{\mathrm{x}} / \mathrm{CeO}_{2}$

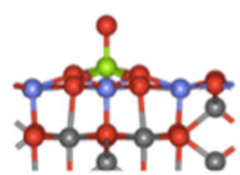

388

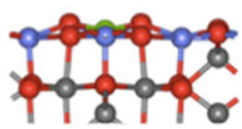

$\mathrm{VO}_{x} / \gamma-\mathrm{Al}_{2} \mathrm{O}_{3}(100)$

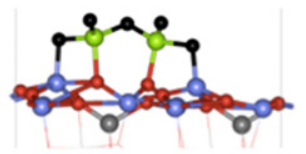

386

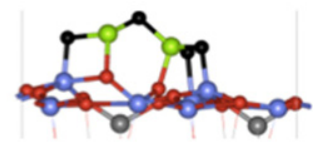

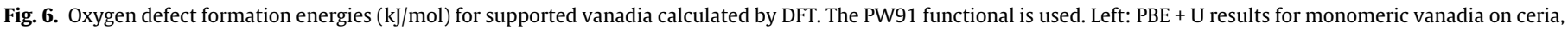
middle and right: PW91 results for monomeric and dimeric vanadia, respectively, on $\gamma$-alumina. 


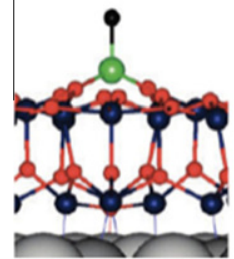

338

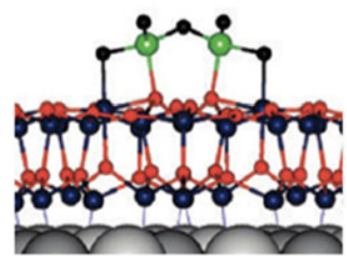

401

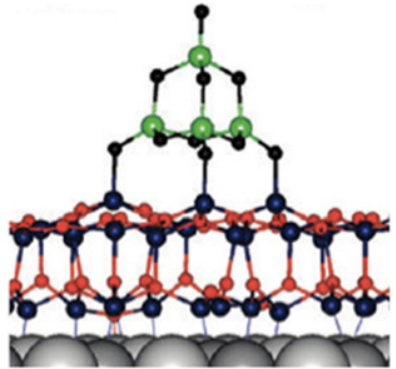

359

Fig. 7. Oxygen defect formation energies $(\mathrm{kJ} / \mathrm{mol})$ for monomeric, dimeric, and tetrameric vanadia species on the ultrathin alumina/NiAl film.

Fig. 7 shows that the oxygen defect formation energies for monomeric, dimeric, and tetrameric vanadia species on the thinfilm alumina/NiAl support are in the same range $(338-401 \mathrm{~kJ} /$ $\mathrm{mol}$ ) as the results for the monomeric and dimeric species on the $\gamma$-alumina surface. Hence, the reactivity of vanadia species on the alumina model catalyst as used for the experiments in Fig. 5 should be comparable to that of small vanadia particles present on the surface of powder catalysts (Tables 4 and 5).

\section{Discussion}

The oxygen defect formation energies obtained by DFT (Figs. 6 and 7) indicate that the thin alumina film on NiAl is a good model for the $\gamma$-alumina support among the powder catalysts. Both the observed (impedance spectroscopy, Table 3) and DFT-calculated (Fig. 6) differences of oxygen defect formation energies between ceria and alumina supports explain the observed reactivity differences at these samples.

DFT calculations have also been performed for vanadia supported on zirconia [75]. Whereas for isolated dimeric vanadia species, the calculated values for zirconia $(389 \mathrm{~kJ} / \mathrm{mol})$ are hardly different from the ones for alumina (386-401 kJ/mol, Figs. 6 and $7)$, significantly lower values (150-190 kJ/mol) have been obtained by DFT only for polymeric vanadia species on zirconia supports [75].

Previous studies have shown a strong influence of the support material on the ODH rate of various reactants like methanol, ethane, and propane. Even though different conditions, that is temperature and feed composition, were used, they found the same ranking of activity, which is $\mathrm{TiO}_{2}>\mathrm{ZrO}_{2}>\mathrm{CeO}_{2}>\mathrm{Al}_{2} \mathrm{O}_{3}>\mathrm{SiO}_{2}$ $[3,6,8,9]$. An exception is methanol $\mathrm{ODH}$, for which the observed reactivity sequence was $\mathrm{CeO}_{2}>\mathrm{ZrO}_{2}>\mathrm{TiO}_{2}>\mathrm{Al}_{2} \mathrm{O}_{3}>\mathrm{SiO}_{2}$ [1]. This support effect was also found for the oxidation of propene to acrolein [76]. However, one must interpret this observation with great care since the oxidation to acrolein is a $4 \mathrm{e}^{-}$reaction requiring two surface vanadyl sites and is showing a strong influence by the vanadium surface density [76]. Whereas we found the same activity ranking when pure vanadia is excluded (Fig. 8, top). A plot of the apparent activation energies even exhibits a strong correlation (Fig. 8, bottom).

Clearly, the close relationship between the apparent activation energies of ethanol and propane $\mathrm{ODH}$ as a function of the support material is manifested here as a straight line through the point of origin with $23 \pm 5 \mathrm{~kJ} / \mathrm{mol}$ lower barriers for ethanol oxidation. This indicates that the rate-limiting steps of both reactions are influenced by the same phenomena. This is reasonable, since hydrogen abstraction has been shown to be the rate-determining step for both methanol and propane oxidation reactions $[11,12]$. For $\mathrm{VO}_{x} /$ $\mathrm{SiO}_{2}$ catalysts, the predicted apparent Arrhenius barrier (DFT) for methanol of $104 \pm 5 \mathrm{~kJ} / \mathrm{mol}=\left(\Delta \mathrm{H}_{503}^{\#}+\mathrm{R} \cdot 503+\Delta \mathrm{CCSD}(\mathrm{T})\right)[12]$ is also about $20 \mathrm{~kJ} / \mathrm{mol}$ lower than that predicted for propane, $123 \pm 5 \mathrm{~kJ} / \mathrm{mol}=\left(\Delta \mathrm{H}_{750}^{\#}+\mathrm{R} \cdot 750\right)[11]$.
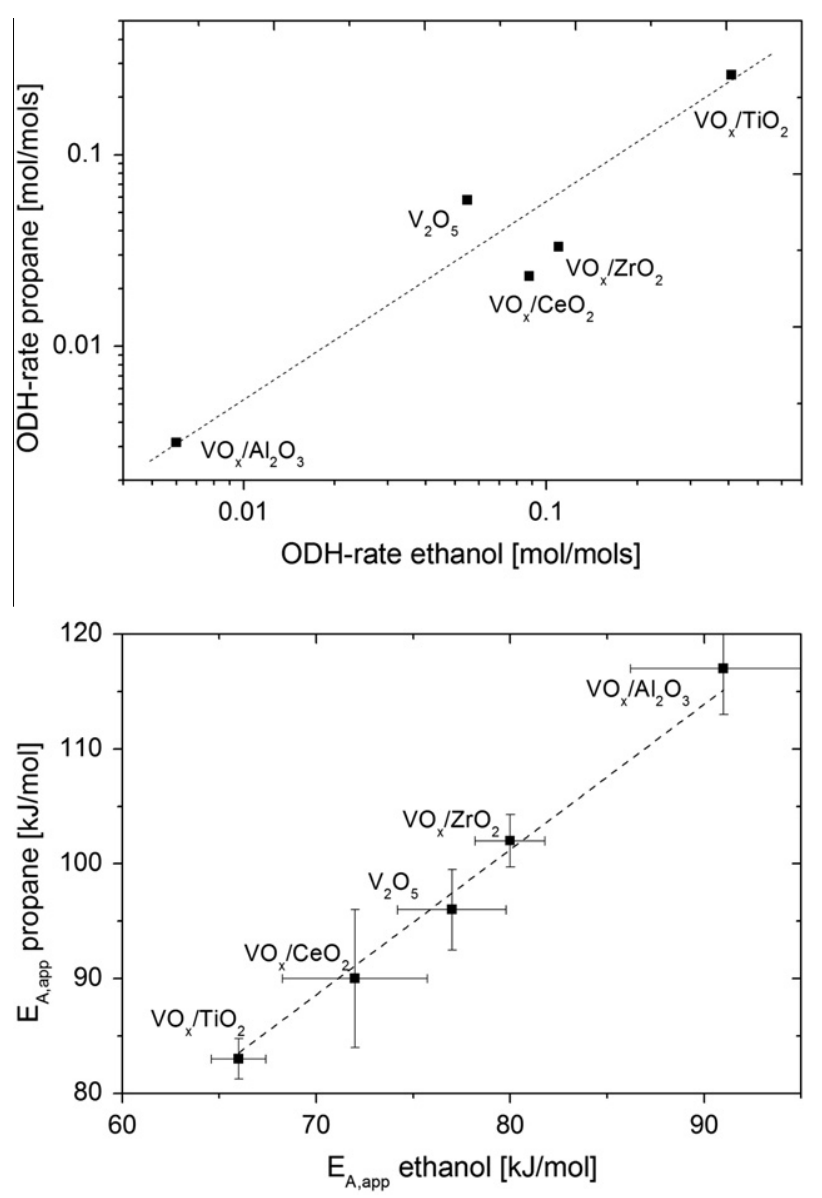

Fig. 8. Correlation of propane and ethanol ODH rates (top) and apparent activation energies (bottom).

Therefore, the TPD and IRAS results on vanadia thin-film model catalysts clearly show the support effect such that vanadia supported on ceria is more active toward ethanol than vanadia supported on alumina.

Every support material exhibits unique features, which may influence the catalytic performance. Electron paramagnetic resonance (EPR) measurements indicate the presence of small amounts of vanadium (IV) deposited on alumina, even under an oxidizing atmosphere [77]. This could be inactive for the ODH reaction. At elevated temperatures ceria can form a $\mathrm{CeVO}_{4}$-phase, which is inactive for the $\mathrm{ODH}$ of ethanol. $\mathrm{CeVO}_{4}$ formation is favored with increasing surface coverage of vanadium and under typical ODH reaction conditions [58]. Ceria and titania are partially reduced to oxidation state three under reaction conditions via reoxidation of 
the supported vanadium centers to oxidation state $5+[58,77,78]$. Especially, ceria stabilizes vanadium in the oxidation state +5 in the presence of oxygen by creating $\mathrm{Ce}^{3+}$ ions [48].

Since hydrogen abstraction has been shown to be the ratedetermining step for the oxidation of alcohol to aldehyde [12], the hydrogenation energy

$\mathrm{VO}_{x}+\mathrm{H}_{2} \rightarrow \mathrm{VO}_{x-1}+\mathrm{H}_{2} \mathrm{O}$

is often used as reactivity descriptor [14]. Fig. 9 shows that there is a correlation between the temperature at maximum acetaldehyde production during TPR of ethanol and the ODH rate of the catalysts. However, such correlation does not exist with the reducibility as measured in the $\mathrm{H}_{2}$-TPR experiments. Nevertheless, the EtOH-TPR experiments provide evidence that vanadium is only reduced to the oxidation state IV.

As mentioned previously, several authors tried, more or less successfully, to correlate the ODH rate with the reducibility of the surface vanadyl species [6,79]. Oxygen defect formation also leads to a (partially) reduced catalyst, and hence, the oxygen defect formation energy has been also suggested as reactivity descriptor $[13,15,75,80]$

$\mathrm{VO}_{x} \rightarrow \mathrm{VO}_{x-1}+0.5 \mathrm{O}_{2}$

Fig. 10 shows the proposed energy profile of the oxidation of ethanol exemplary for vanadia supported on alumina, beginning with the oxidized state of the catalyst and the reactants in the gas phase. A similar reaction energy profile has been obtained by DFT for the methanol oxidation on vanadia supported on silica [12]. The first step is the adsorption of ethanol,

$$
\begin{aligned}
& \mathrm{V}^{\mathrm{V}} \mathrm{V}^{\mathrm{V}} \mathrm{O}_{2}+\mathrm{C}_{2} \mathrm{H}_{5} \mathrm{OH}(\mathrm{g})+0.5 \mathrm{O}_{2}(\mathrm{~g}) \\
& \rightarrow \mathrm{V}^{\mathrm{V}} \mathrm{V}^{\mathrm{V}} \mathrm{O}(\mathrm{OH})\left(\mathrm{OC}_{2} \mathrm{H}_{5}\right)+0.5 \mathrm{O}_{2}(\mathrm{~g}) .
\end{aligned}
$$

It is followed by the rate-limiting step, abstraction of hydrogen, occurring via transition state "TS," where the catalyst is partially reduced:

$$
\begin{aligned}
\mathrm{V}^{\mathrm{V}} \mathrm{V}^{\mathrm{V}} \mathrm{O}(\mathrm{OH})\left(\mathrm{OC}_{2} \mathrm{H}_{5}\right) & \rightarrow\left[\mathrm{V}^{\mathrm{V}} \mathrm{V}^{\mathrm{IV}}(\mathrm{OH})_{2}\left(\mathrm{OC}_{2} \mathrm{H}_{4}^{-}\right)\right]^{\dagger} \\
& \rightarrow \mathrm{V}^{\mathrm{IV}} \mathrm{V}^{\mathrm{IV}}(\mathrm{OH})_{2}\left(\mathrm{OC}_{2} \mathrm{H}_{4}\right) / \mathrm{V}^{\mathrm{V}} \mathrm{V}^{\mathrm{III}} \mathrm{O}\left(\mathrm{H}_{2} \mathrm{O}\right)\left(\mathrm{OC}_{2} \mathrm{H}_{4}\right)
\end{aligned}
$$

Experimentally, it is only possible to measure the energy difference between before the adsorption of ethanol and the formation of "TS" in a steady state experiment. This is the apparent activation energy, $E_{a, a p p}$, which includes the adsorption enthalpy, $\Delta H_{a}\left(\mathrm{C}_{2} \mathrm{H}_{5} \mathrm{OH}\right)$, and the intrinsic barrier for the rate-limiting step. An estimate of the adsorption energy $\Delta H_{a}\left(\mathrm{C}_{2} \mathrm{H}_{5} \mathrm{OH}\right) \approx 48 \mathrm{~kJ} / \mathrm{mol}$ is obtained from

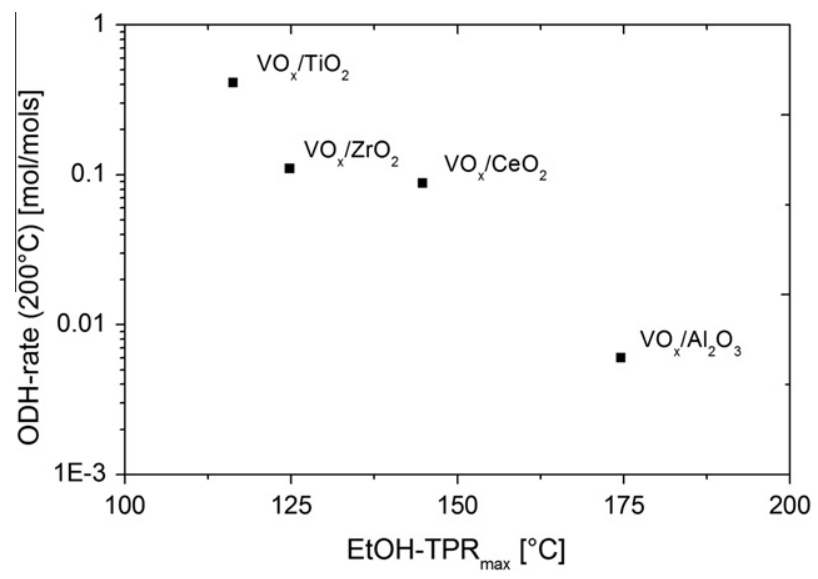

Fig. 9. Comparison of EtOH-TPR maxima with ODH rate of EtOH.

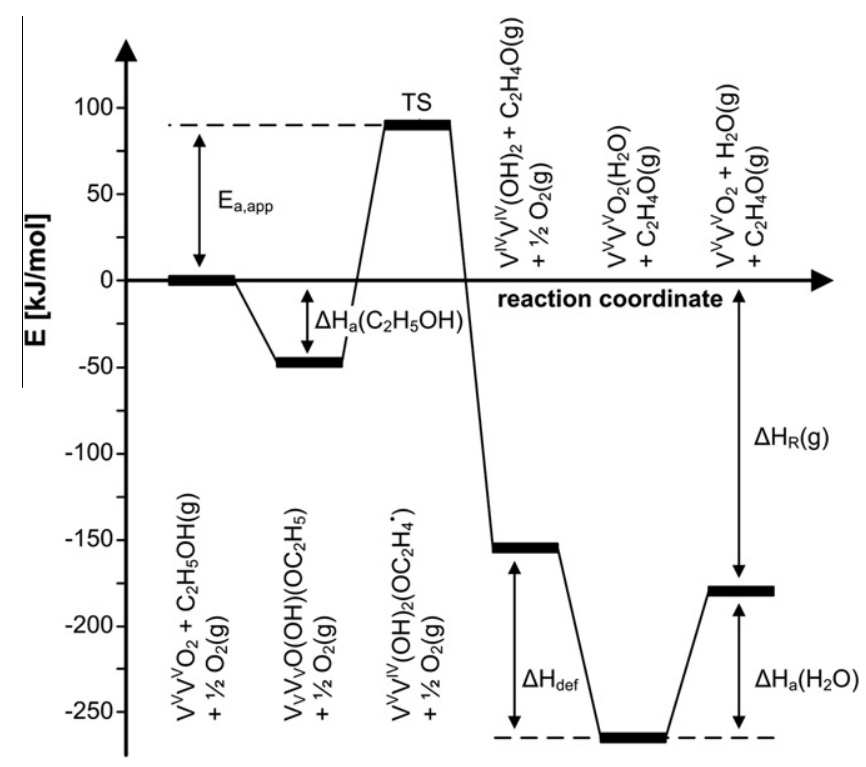

Fig. 10. Proposed energy profile of the oxidation of ethanol at vanadium supported on alumina.

$\Delta H_{a}\left(\mathrm{CH}_{3} \mathrm{OH}\right)=38 \mathrm{~kJ} / \mathrm{mol}$ [12] plus an increment of $10 \mathrm{~kJ} / \mathrm{mol}$ for the $\mathrm{CH}_{2}$ group. The product formation involves the formation of two V(IV) atoms and the desorption of acetaldehyde:

$\mathrm{V}^{\mathrm{IV}} \mathrm{V}^{\mathrm{IV}}(\mathrm{OH})_{2}\left(\mathrm{OC}_{2} \mathrm{H}_{4}\right) \rightarrow \mathrm{V}^{\mathrm{IV}} \mathrm{V}^{\mathrm{IV}}(\mathrm{OH})_{2}+\mathrm{C}_{2} \mathrm{H}_{4} \mathrm{O}(\mathrm{g})$

The last step is the oxidation of the catalyst by oxygen.

$\mathrm{V}^{\mathrm{IV}} \mathrm{V}^{\mathrm{IV}}(\mathrm{OH})_{2}+0.5 \mathrm{O}_{2}(\mathrm{~g}) \rightarrow \mathrm{V}^{\mathrm{V}} \mathrm{V}^{\mathrm{V}} \mathrm{O}_{2}\left(\mathrm{H}_{2} \mathrm{O}\right)$

The enthalpy of oxidation corresponds to the inverse of the enthalpy of defect formation, $\Delta H_{d e f}=111 \mathrm{~kJ} / \mathrm{mol}$, Table 5). Desorption of water $\left(\Delta H_{a}\left(\mathrm{H}_{2} \mathrm{O}\right)=-86 \mathrm{~kJ} / \mathrm{mol}[71]\right)$ formally completes the reaction cycle and connects with the gas phase reaction to the overall reaction enthalpy, $\Delta H_{R}=-179 \mathrm{~kJ} / \mathrm{mol}$.

$\mathrm{C}_{2} \mathrm{H}_{5} \mathrm{OH}(\mathrm{g})+0.5 \mathrm{O}_{2}(\mathrm{~g}) \rightarrow \mathrm{C}_{2} \mathrm{H}_{4} \mathrm{O}(\mathrm{g})+\mathrm{H}_{2} \mathrm{O}(\mathrm{g})$

By altering the support, the oxygen defect formation enthalpy can decreased, which is followed by a decrease in the apparent activation energy as it is shown by the correlations in Fig. 11.

Fig. 11 shows the apparent activation energy as function of the oxygen defect formation energy. When the values for pure vanadia are omitted, there a very good linear correlation with $r=0.999$. The

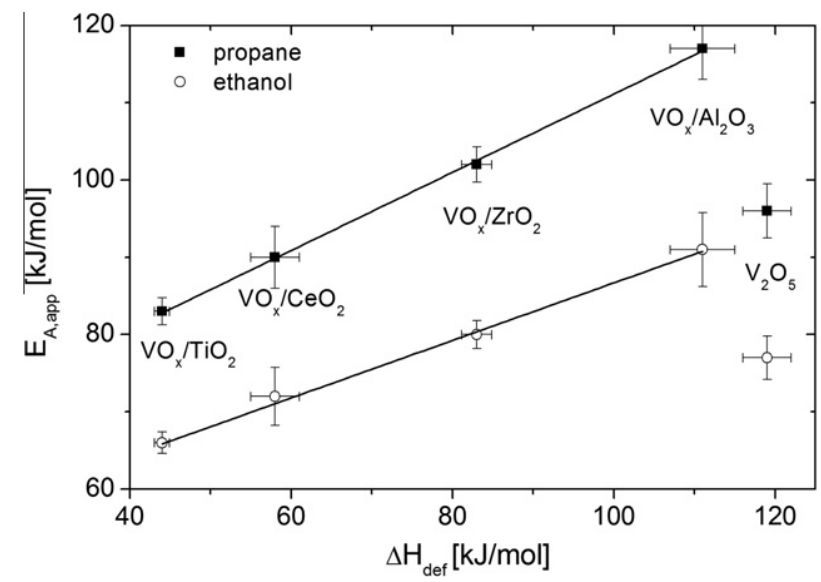

Fig. 11. Correlation of defect formation enthalpy with activation energy of propane and ethanol oxidation. 
straight line has a positive $y$-axis intercept at $\Delta H_{d e f}=0$, which is located at $60 \mathrm{~kJ} / \mathrm{mol}$ for propane and at $50 \mathrm{~kJ} / \mathrm{mol}$ for ethanol. This is attributed to the different strengths of the $\mathrm{C}-\mathrm{H}$ bonds involved in the dehydration. The inconsistency of the $\mathrm{V}_{2} \mathrm{O}_{5}$ defect formation enthalpy is probably related to defect formation in the bulk instead of only on the surface.

\section{Conclusion}

We found the same support effect for thin-film model catalysts as for powder catalysts and have demonstrated that this is not simply a phenomenon of the bulk phase. Moreover, the vanadia powder catalysts show the same reactivity across different supports for ethanol oxidation and for propane oxidation. Despite the fact that the oxidic catalyst system and the reaction are clearly different, similar correlations were found by varying the support material. The observed correlation between the apparent activation energies of the ODH of ethanol and propane with the measured oxygen defect formation enthalpies shows that the reducibility of supported vanadia can be used as reactivity descriptor as suggested before $[13-15,80]$

The derived data demonstrate that the reaction follows very similar energy profiles with changes that are governed by defect formation energies according to the Bell-Evans-Polanyi principle as expressed in the following formula.

$E_{A}=\alpha \Delta E+\beta$,

with $E_{A}$ as activation energy of the rate-determining step, $\Delta E$ as reaction energy of the key reaction step, $\alpha$ and $\beta$ as scaling parameters. Since this depends strongly on the support material, an optimization of the catalyst should consider measures for tuning the reducibility of the vanadia supported thereon. With doped or mixed oxides, this is possible in a wide range.

In oxidation reactions, the difference between the rates of desired product formation and undesired over oxidation and also of the activation energies of these reactions is mainly governed by the difference in the $\mathrm{C}-\mathrm{H}$ bond strength involved in the corresponding rate-determining steps. Since these parameters cannot be changed for a given reaction, it is necessary to select a reaction temperature where the ratio between the rates of desired and undesired reaction is sufficiently high for achieving a reasonable selectivity. In order to obtain also a suitable space-time yield at this temperature, it is important to have a tuning parameter available that adjusts the reaction rate at the selected temperature in an economically viable range.

\section{Acknowledgments}

We thank the Deutsche Forschungsgemeinschaft for the financial support of our work in the Sonderforschungsbereich 546 and especially the recently late Prof. Helmut Schubert for his valuable contribution to this work.

\section{References}

[1] I.E. Wachs, Catal. Today 100 (2005) 79-94.

[2] B. Kilos, A.T. Bell, E. Iglesia, J. Phys. Chem. C 113 (2009) 2830-2836

[3] A. Dinse, B. Frank, C. Hess, D. Habel, R. Schomäcker, J. Mol. Catal. A: Chem. 289 (2008) 28-37.

[4] T. Blasco, J.M.L. Nieto, Appl. Catal., A 157 (1997) 117-142.

[5] P. Eisele, R. Killpack, Ullmann's Encyclopedia of Industrial Chemistry (2000).

[6] M. Banares, M. Martinez-Huerta, X. Gao, Catal. Today 61 (2000) 295-301.

[7] A. Khodakov, B. Olthof, A.T. Bell, E. Iglesia, J. Catal. 181 (1999) 205-216.

[8] A.A. Lemonidou, L. Nalbandian, I.A. Vasalos, Catal. Today 61 (2000) 333-341.

[9] H. Tian, E.I. Ross, I.E. Wachs, J. Phys. Chem. B 110 (2006) 9593-9600.

[10] G. Deo, I.E. Wachs, J. Catal. 146 (1994) 323-334.

[11] X. Rozanska, R. Fortrie, J. Sauer, J. Phys. Chem. C 111 (2007) 6041-6050.

[12] J. Döbler, M. Pritzsche, J. Sauer, J. Am. Chem. Soc. 127 (2005) 10861-10868.
[13] J. Sauer, J. Dobler, Dalton Trans. (2004) 3116-3121.

[14] J. Sauer, in: K. Morokuma, D.G. Musaev (Eds.), Computational Modelling for Homogeneous and Enzymatic Catalysis, Wiley-VCH, Weinheim, 2008, pp. 231-244.

[15] M.V. Ganduglia-Pirovano, C. Popa, J. Sauer, H. Abbott, A. Uhl, M. Baron, D. Stacchiola, O. Bondarchuk, S. Shaikhutdinov, H.-J. Freund, J. Am. Chem. Soc. 132 (2010) 2345-2349.

[16] R.P. Bell, Proc. R. Soc. A 154 (1936) 414-429.

[17] N.E. Quaranta, J. Soria, V. Cortés Corberán, J.L.G. Fierro, J. Catal. 13 (1997) 1-13.

[18] Y.-C. Lin, C.-H. Chang, C.-C. Chen, J.-M. Jehng, S.-G. Shyu, Catal. Commun. 9 (2008) 675-679.

[19] M. Baron, O. Bondarchuk, D. Stacchiola, S. Shaikhutdinov, H.J. Freund, J. Phys Chem. C 113 (2009) 6042-6049.

[20] D.R. Mullins, L. Kundakovic, S.H. Overbury, J. Catal. 195 (2000) 169-179.

[21] R. Jaeger, H. Kuhlenbeck, H.J. Freund, M. Wuttig, W. Hoffmann, R. Franchy, H. Ibach, Surf. Sci. 259 (1991) 235-252.

[22] N. Magg, J.B. Giorgi, T. Schroeder, M. Bäumer, H.J. Freund, J. Phys. Chem. B 106 (2002) 8756-8761.

[23] C. Popa, M.V. Ganduglia-Pirovano, J. Sauer, J. Phys. Chem. C 115 (2011) 73997410.

[24] V. Brazdova, M.V. Ganduglia-Pirovano, J. Sauer, J. Phys. Chem. C 114 (2010) 4983-4994.

[25] W.N. Delgass, Spectroscopy in Heterogeneous Catalysis, Academic Press, New York, 1979.

[26] M. Harth, R. Mitdank, D. Habel, O. Görke, M. Tovar, H. Winter, H. Schubert, Int J. Mater. Res. (2012), in press.

[27] A. Khodakov, J. Yang, S. Su, E. Iglesia, A.T. Bell, J. Catal. 177 (1998) 343-351.

[28] G. Centi, Appl. Catal., A 147 (1996) 267-298.

[29] M. Iwamoto, H. Furukawa, K. Matsukami, T. Takenaka, S. Kagawa, J. Am. Chem. Soc. 105 (1983) 3719-3720.

[30] H. So, M.T. Pope, Inorg. Chem. 11 (1972) 1441-1443.

[31] E.F. King, M.L. Good, Spectrochim. Acta, Part A 29 (1973) 707-713.

[32] A.P. Alivisatos, Science 271 (1996) 933-937.

[33] N. Chestnoy, R. Hull, L.E. Brus, J. Chem. Phys. 85 (1986) 2237

[34] C.F. Hoener, K.A. Allan, A.J. Bard, A. Campion, M.A. Fox, T.E. Mallouk, S.E Webber, J.M. White, J. Phys. Chem. 96 (1992) 3812-3817.

[35] Z. Liu, R.J. Davis, J. Phys. Chem. 98 (1994) 1253-1261.

[36] Z. Wu, H.-S. Kim, P.C. Stair, S. Rugmini, S.D. Jackson, J. Phys. Chem. B 109 (2005) 2793-2800.

[37] P. Gruene, T. Wolfram, K. Pelzer, R. Schlögl, A. Trunschke, Catal. Today 157 (2010) 137-142.

[38] D.I. Enache, E. Bordes-Richard, A. Ensuque, F. Bozon-Verduraz, Appl. Catal., A 278 (2004) 93-102.

[39] M. Schraml-Marth, A. Wokaun, M. Pohl, H.-L. Krauss, J. Chem. Soc., Faraday Trans. 87 (1991) 2635

[40] F. Arena, F. Frusteri, G. Martra, S. Coluccia, A. Parmaliana, J. Chem. Soc. Faraday Trans. 93 (1997) 3849-3854.

[41] Y.-M. Liu, Y. Cao, N. Yi, W.-L. Feng, W.-L. Dai, S.-R. Yan, H.-Y. He, K.-N. Fan, J Catal. 224 (2004) 417-428.

[42] X. Gao, S.R. Bare, B.M. Weckhuysen, I.E. Wachs, J. Phys. Chem. B 102 (1998) 10842-10852.

[43] J. Bullot, P. Cordier, O. Gallais, M. Gauthier, F. Babonneau, J. Non-Cryst. Solids 68 (1984) 135-146.

[44] W. Weber, K. Hass, J. McBride, Phys. Rev. B: Condens. Matter Mater. Phys. 48 (1993) 178-185

[45] C.M. Phillippi, K.S. Mazdiyasni, J. Am. Ceram. Soc. 54 (1971) 254-258.

[46] L. Abello, E. Husson, Y. Repelin, G. Lucazeau, Spectrochim. Acta, Part A 39 (1983) 641-651.

[47] Z. Wu, A.J. Rondinone, I.N. Ivanov, S.H. Overbury, J. Phys. Chem. C 115 (2011) 25368-25378

[48] M. Baron, H. Abbott, O. Bondarchuk, D. Stacchiola, A. Uhl, S. Shaikhutdinov, H.J. Freund, C. Popa, M.V. Ganduglia-Pirovano, J. Sauer, Angew. Chem. Int. Ed. 48 (2009) 8006-8009.

[49] M.V. Martinez-Huerta, G. Deo, J.L.G. Fierro, M.A. Banares, J. Phys. Chem. C 111 (2007) 18708-18714.

[50] A. Christodoulakis, M. Machli, A.A. Lemonidou, S. Boghosian, J. Catal. 222 (2004) 293-306.

[51] G. Cortez, M.A. Bañares, J. Catal. 209 (2002) 197-201.

[52] I.E. Wachs, Catal. Today 27 (1996) 437-455

[53] M.A. Bañares, I.E. Wachs, J. Raman Spectrosc. 33 (2002) 359-380.

[54] S.T. Oyama, G.T. Went, K.B. Lewis, A.T. Bell, G.A. Somorjai, J. Phys. Chem. 93 (1989) 6786-6790.

[55] G.T. Went, S.T. Oyama, A.T. Bell, J. Phys. Chem. 94 (1990) 4240-4246.

[56] J.-M. Jehng, G. Deo, B.M. Weckhuysen, I.E. Wachs, J. Mol. Catal. A: Chem. 110 (1996) 41-54.

[57] L.J. Burcham, I.E. Wachs, Catal. Today 49 (1999) 467-484.

[58] M.V. Martínez-Huerta, J.M. Coronado, M. Fernández-García, A. Iglesias-Juez, G Deo, J.L.G. Fierro, M.A. Banares, J. Catal. 225 (2004) 240-248.

[59] H. Dai, A.T. Bell, E. Iglesia, J. Catal. 221 (2004) 491-499.

[60] G. Busca, Mater. Chem. Phys. 19 (1988) 157-165.

[61] G. Busca, J.C. Lavalley, Spectrochim. Acta, Part A 42 (1986) 443-445.

[62] J.P. Dunn, H.G. Stenger, I.E. Wachs, Catal. Today 53 (1999) 543-556.

[63] G. Busca, J. Raman Spectrosc. 33 (2002) 348-358.

[64] L. Lietti, P. Forzatti, G. Ramis, G. Busca, F. Bregani, Appl. Catal., B 3 (1993) 13-35

[65] M.M. Ostromecki, L.J. Burcham, I.E. Wachs, J. Mol. Catal. A: Chem. 132 (1998) 59-71. 
[66] H. Selig, H.H. Claassen, J. Chem. Phys. 44 (1966) 1404.

[67] F.A. Miller, L.R. Cousins, J. Chem. Phys. 26 (1957) 329.

[68] N. Magg, B. Immaraporn, J.B. Giorgi, T. Schroeder, M. Bäumer, J. Döbler, Z. Wu, E.V. Kondratenko, M. Cherian, M. Baerns, P.C. Stair, J. Sauer, H.-J. Freund, J. Catal. 226 (2004) 88-100.

[69] M. Harth, Characterization of the Catalytic Properties of Supported $\mathrm{VO}_{x^{-}}$ catalysts Using Electrochemical Methods, 2011.

[70] T. Allersma, R. Hakim, T.N. Kennedy, J.D. Mackenzie, J. Chem. Phys. 46 (1967) 154.

[71] X. Rozanska, E.V. Kondratenko, J. Sauer, J. Catal. 256 (2008) 84-94.

[72] G. Avgouropoulos, E. Oikonomopoulos, D. Kanistras, T. Ioannides, Appl. Catal., B 65 (2006) 62-69.
[73] H.L. Abbott, A. Uhl, M. Baron, Y. Lei, R.J. Meyer, D.J. Stacchiola, O. Bondarchuk, S. Shaikhutdinov, H.J. Freund, J. Catal. 272 (2010) 82-91.

[74] M. Martinez-Huerta, G. Deo, J. Phys. Chem. C (2008) 11441-11447.

[75] A. Hofmann, M.V. Ganduglia-Pirovano, J. Sauer, J. Phys. Chem. C 113 (2009) 18191-18203.

[76] C. Zhao, I. Wachs, J. Catal. 257 (2008) 181-189.

[77] A. Dinse, A. Ozarowski, C. Hess, R. Schomäcker, K.P. Dinse, J. Phys. Chem. C 112 (2008) 17664-17671.

[78] G. Wong, J. Vohs, Surf. Sci. 498 (2002) 266-274.

[79] H. Feng, J.W. Elam, J.A. Libera, M.J. Pellin, P.C. Stair, J. Catal. 269 (2010) 421-431.

[80] H.Y. Kim, H.M. Lee, R.G.S. Pala, V. Shapovalov, H. Metiu, J. Phys. Chem. C 112 (2008) 12398-12408. 